\title{
Annual dialysis data report of the 2018 JSDT Renal Data Registry: dementia, performance status, and exercise habits
}

\author{
Kosaku Nitta', Shigeru Nakai ${ }^{1,2^{*}}$ (D, Ikuto Masakane ${ }^{1}$, Norio Hanafusa ${ }^{1}$, Shunsuke Goto ${ }^{1}$, Masatomo Taniguchi ${ }^{1}$, \\ Takeshi Hasegawa” ${ }^{1}$ Atsushi Wada', Takayuki Hamano ${ }^{1}$, Junichi Hoshino ${ }^{1}$, Nobuhiko Joki ${ }^{1}$, Keichi Yamamoto ${ }^{1}$, \\ Kenichiro Miura ${ }^{1}$, Masanori Abe ${ }^{1}$, Hidetomo Nakamoto ${ }^{1}$ and on behalf of Japanese Society for Dialysis Therapy
} Renal Data Registry Committee

\begin{abstract}
According to the annual survey of the Japanese Society for Dialysis Therapy Renal Data Registry (JRDR) conducted at the end of 2018, there were a total of 339,841 patients receiving dialysis (hereinafter, dialysis patients) in Japan. The survey included questions regarding the presence/absence of dementia, the performance status (PS), and the exercise habits of individual patients. The survey revealed that $10.8 \%$ of all dialysis patients had dementia (1.8\% in the age group of less than 65 years, $6.8 \%$ in the age group of $65-74$ years, and $22.7 \%$ in the age group of 75 years or older). These prevalences of dementia were approximately equal to those estimated from the survey conducted in 2010. Regarding PS, the percentage of patients with lower activity levels tended to be relatively high among patients who were less than 15 years old and those who were 60 years old or older. Concerning the exercise habits of dialysis patients, the percentage of patients who were classified as "not at all or hardly" in response to the question about exercise habit was the highest (60-80\%) of all the exercise habit classifications in each of the age groups analyzed.
\end{abstract}

Keywords: Dialysis, Registry, Dementia, Performance status, Exercise habits

\section{Introduction}

Since 1968, the Japanese Society for Dialysis Therapy (JSDT) has conducted a survey examining the status of chronic dialysis treatment in Japan at the end of every year. This survey, known as the JSDT Renal Data Registry (JRDR), covers nearly all dialysis facilities in Japan [1, 2]. Although these facilities participate voluntarily, the response rate is nearly $100 \%$, suggesting that this survey represents the real-world status of regular dialysis in

\footnotetext{
* Correspondence: s-nakai@fujita-hu.ac.jp

'Japanese Society for Dialysis Therapy Renal Data Registry Committee, Japanese Society for Dialysis Therapy, Tokyo, Japan

${ }^{2}$ Faculty of Clinical Engineering Technology, Fujita Health University School of Health Sciences, Dengakugakubo 1-98, Kutsukake-cho, Toyoake, Aichi 470-1192, Japan
}

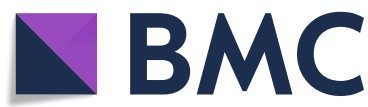

(c) The Author(s). 2021 Open Access This article is licensed under a Creative Commons Attribution 4.0 International License, which permits use, sharing, adaptation, distribution and reproduction in any medium or format, as long as you give appropriate credit to the original author(s) and the source, provide a link to the Creative Commons licence, and indicate if changes were made. The images or other third party material in this article are included in the article's Creative Commons licence, unless indicated otherwise in a credit line to the material. If material is not included in the article's Creative Commons licence and your intended use is not permitted by statutory regulation or exceeds the permitted use, you will need to obtain permission directly from the copyright holder. To view a copy of this licence, visit http://creativecommons.org/licenses/by/4.0/. The Creative Commons Public Domain Dedication waiver (http://creativecommons.org/publicdomain/zero/1.0/) applies to the data made available in this article, unless otherwise stated in a credit line to the data. as the kinetics of chronic dialysis patients and dialysis facilities at the end of 2018, water treatment and hemodiafiltration, peritoneal dialysis, treatments for diabetes and mental and physical conditions, and the present status of viral hepatitis.

This basic research report was prepared to clarify the actual conditions of the prevalence of dementia, PS, and exercise habits among Japanese dialysis patients as of the end of 2018. The report also serves as an English translation of information regarding the presence/absence of dementia, performance status (PS), and exercise habits of dialysis patients in Japan obtained from the JRDR survey conducted at the end of 2018 and published, in 
Japanese, in the Journal of the Japanese Society for Dialysis Therapy [3, 4].

\section{Materials and methods}

Details of the survey conducted in 2018 are given in the report on the basic data from the survey [5]. In this survey, the presence/absence of dementia, PS, and exercise habits of dialysis patients were investigated. The patient survey included questions designed to investigate each survey item. Responses to the basic survey items included in the patient survey were collected from 327,336 patients.

\section{Presence/absence of dementia}

The survey of dialysis patients conducted in 2018 included questions to determine the presence/absence of dementia. The presence/absence of dementia at the time of the initiation of maintenance dialysis was first included as a question in the 2006 and 2007 surveys [6, 7]. In 2009 and 2010, the presence/absence of dementia was investigated for the entire survey population of dialysis patients $[8,9]$.

Dementia is defined as follows in the 10th version of the International Classification of Diseases, Injuries, and Causes of Death (ICD10): "dementia is a syndrome due to disease of the brain, usually of chronic or progressive nature, in which there is impairment of multiple higher cortical functions, including memory, thinking, orientation, calculation, learning capacity, language and judgement" [10]. For the diagnosis of dementia, it is necessary to evaluate the cognitive functions of the patient through interviews of the patient and his/her family members; scales such as the Mini Mental State Examination (MMSE) and Hasegawa dementia rating scale-revised (HDS-R) are usually used [11]. During the current survey, a questionnaire was mailed to each participating facility, requesting the facility to answer the questionnaire about the patients and to return the completed questionnaire to our society. Using this survey design, it was impossible to have experts confirm the dementia
Table 1 Performance status [4]

A (Score 0) Fully active, able to carry on all pre-disease performance without restriction.

B (Score 1) Restricted in physically strenuous activity but ambulatory and able to carry out work of a light or sedentary nature, e.g., light housework, office work.

C (Score 2) Ambulatory and capable of all self-care but unable to carry out any work activities. Up and about more than $50 \%$ of waking hours.

D (Score 3) Capable of only limited self-care, confined to bed or chair more than $50 \%$ of waking hours.

E (Score 4) Completely disabled. Cannot carry on any self-care. Totally confined to bed or chair.

Z Unknown

diagnoses of all the patients being managed at the participating facilities. Thus, the determination of the presence/absence of dementia in this survey was based solely on the inquiry described below and the answer choices contained in the questionnaire.

Please indicate the presence or absence of dementia in the patient at the end of December 2018. "If the patient has not been diagnosed as having dementia by a dementia specialist, the diagnosis made by the patient's main physician based on the patient's status during dialysis treatments or consultations is acceptable.

- Answer choices

A. Without dementia

B. With dementia

Z. Unspecified

In response to the question regarding the presence/absence of dementia during this survey, 250,042 patients (76.4\%) were classified as "Without dementia" or "With dementia."

The proportion of patients who were classified as "With dementia" among all the patients who responded to the question about the presence/absence of dementia

Table 2 Age and dementia prevalence (all dialysis patients)

\begin{tabular}{llllllll}
\hline & $\begin{array}{l}\text { Without } \\
\text { dementia }\end{array}$ & $\begin{array}{l}\text { With } \\
\text { dementia }\end{array}$ & Total & $\begin{array}{l}\text { Dementia } \\
\text { unknown }\end{array}$ & $\begin{array}{l}\text { No information } \\
\text { available }\end{array}$ & $\begin{array}{l}\text { Grand } \\
\text { total }\end{array}$ & $\begin{array}{l}\text { Dementia } \\
\text { prevalence (\%) }\end{array}$ \\
\hline Age $<65$ years & 79,339 & 1452 & 80,791 & 5858 & 18,578 & 105,227 & 1.8 \\
Age 65-74 years & 75,884 & 5503 & 81,387 & 6133 & 18,862 & 106,382 & 6.8 \\
Age 75 years or older & 67,932 & 19,932 & 87,864 & 7287 & 20,576 & 115,727 & 22.7 \\
Total & 223,155 & 26,887 & 250,042 & 19,278 & 58,016 & 327,336 & 10.8 \\
Unspecified/no information \\
$\begin{array}{l}\text { available } \\
\text { Grand total }\end{array}$ & 0 & 0 & 0 & 0 & 0 & 0 & 327,336 \\
\hline
\end{tabular}

The data were obtained from the patient survey 


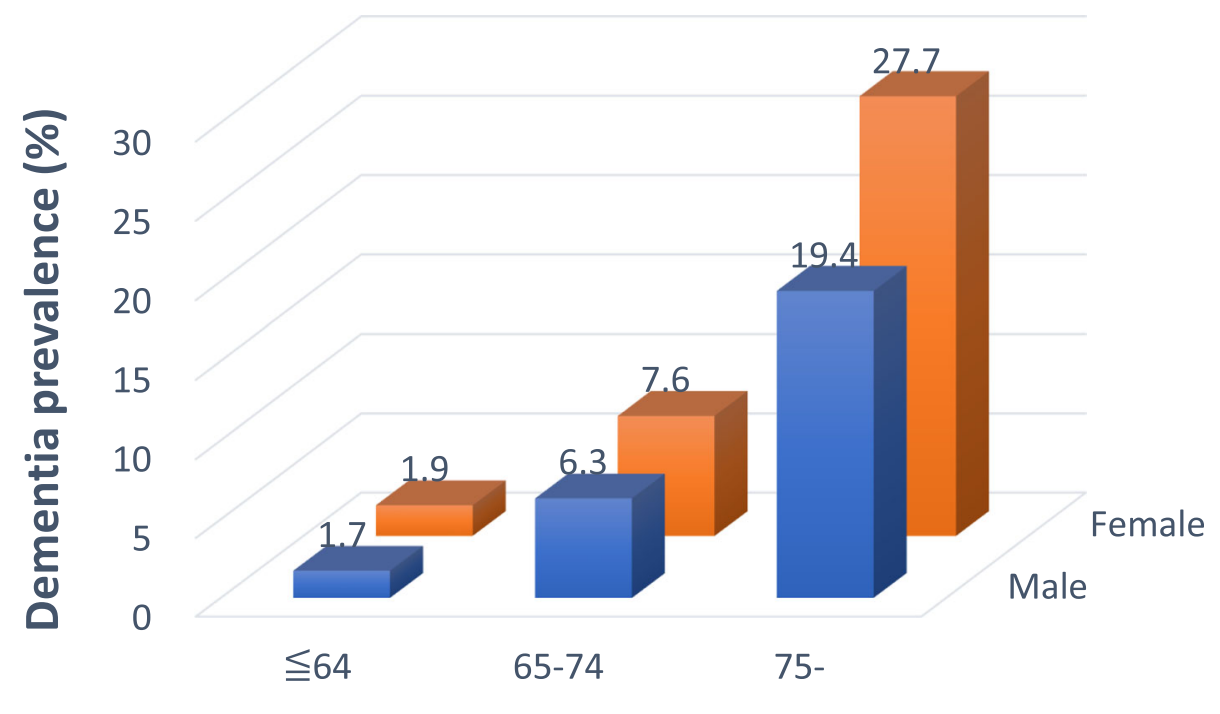

Age (years old)

Fig. 1 Dementia prevalence sorted according to age and sex. Data were obtained from the patient survey

was adopted as the "dementia prevalence." The dementia prevalence was calculated using the equation shown below.

Dementia prevalence $(\%)=[$ number of patients who were classified as “With dementia"]

$\div$ ["number of patients who were classified as "With dementia"

+number of patients who were classified as “Without dementia"] $\times 100$

\section{Performance status (PS)}

The 2018 survey questionnaire contained questions designed to determine the Eastern Cooperative Oncology Group (ECOG) PS of the patients [4] (Table 1).
According to this PS scale, a higher score means a lower physical activity level of the patient. Under this survey program, PS was first investigated in 1998 and was subsequently examined in 2002 and 2009 [8, 12, 13]. In the current survey, valid responses to the questions about PS were collected from 251,609 patients (76.9\%).

\section{Exercise habits}

The 2018 survey questionnaire included, for the first time, questions designed to investigate the exercise habits of dialysis patients. Exercise habits had not been covered by any survey conducted previously within the framework of this survey program. Exercise habits were investigated using the

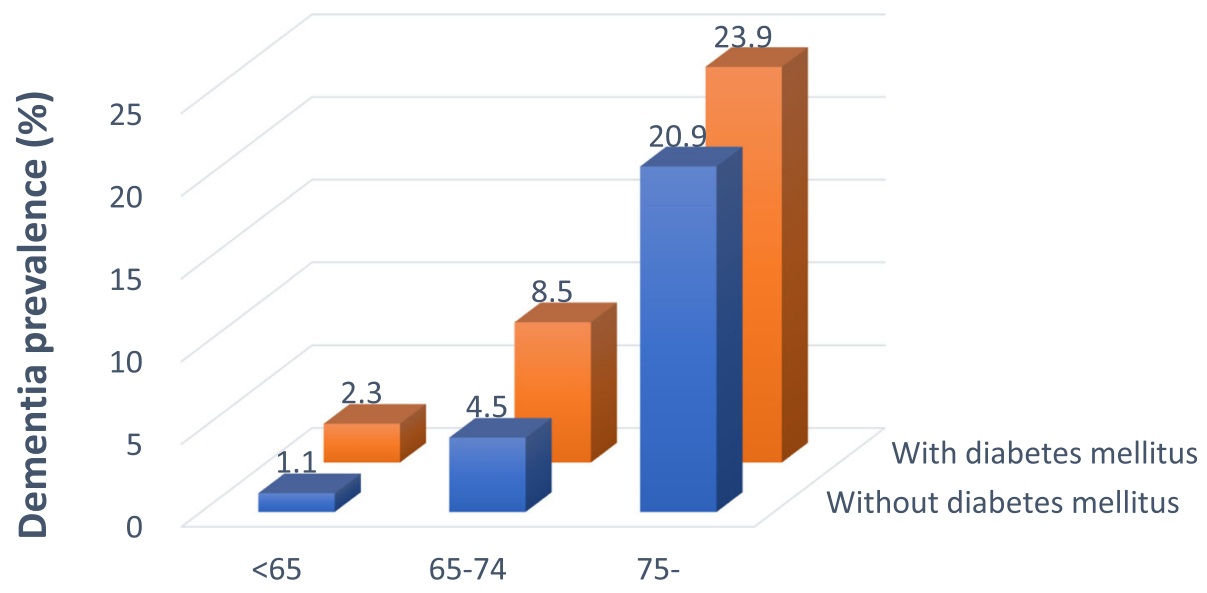

Age (years old)

Fig. 2 Dementia prevalence sorted according to age and diabetic status. Data were obtained from the patient survey 


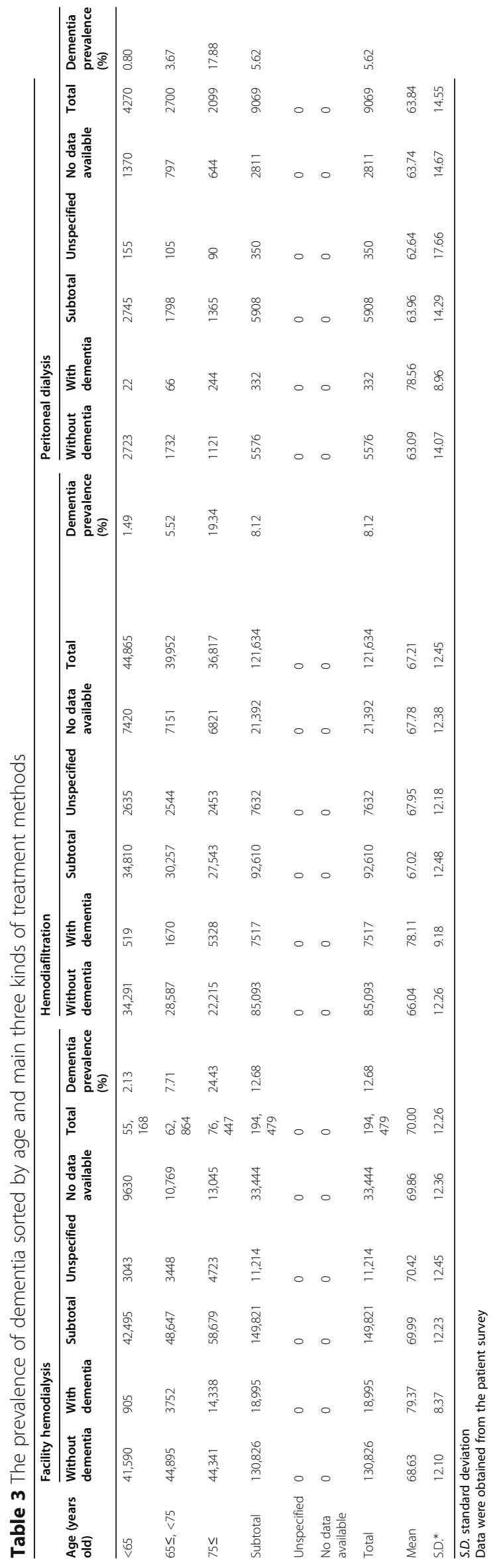




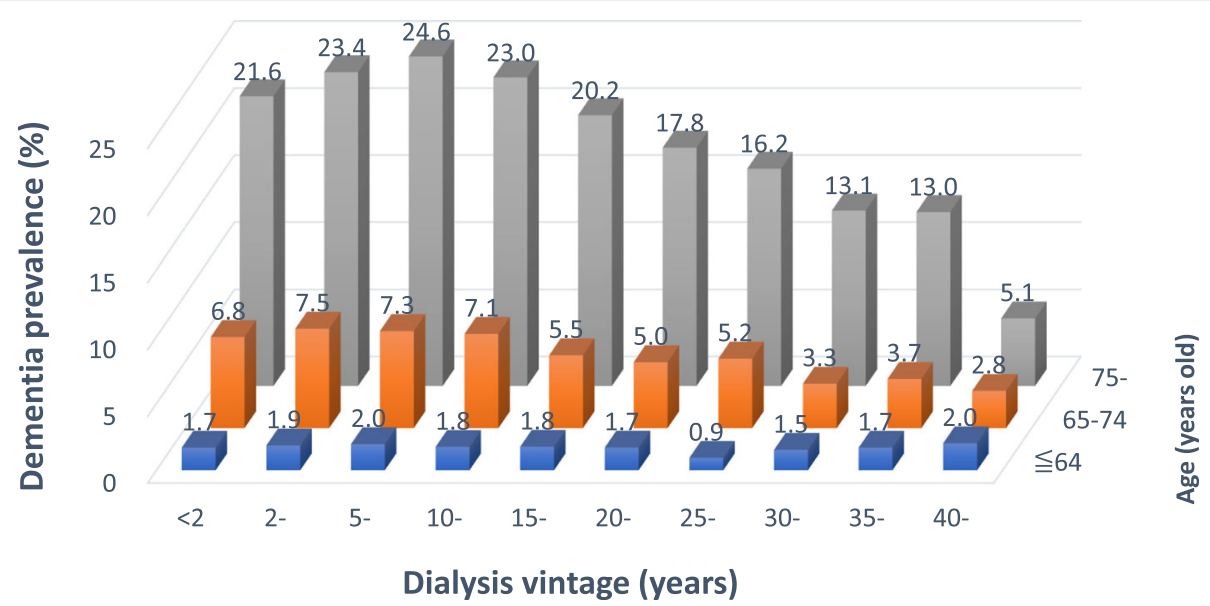

Fig. 3 Dementia prevalence sorted age and dialysis vintage. Data were obtained from the patient survey

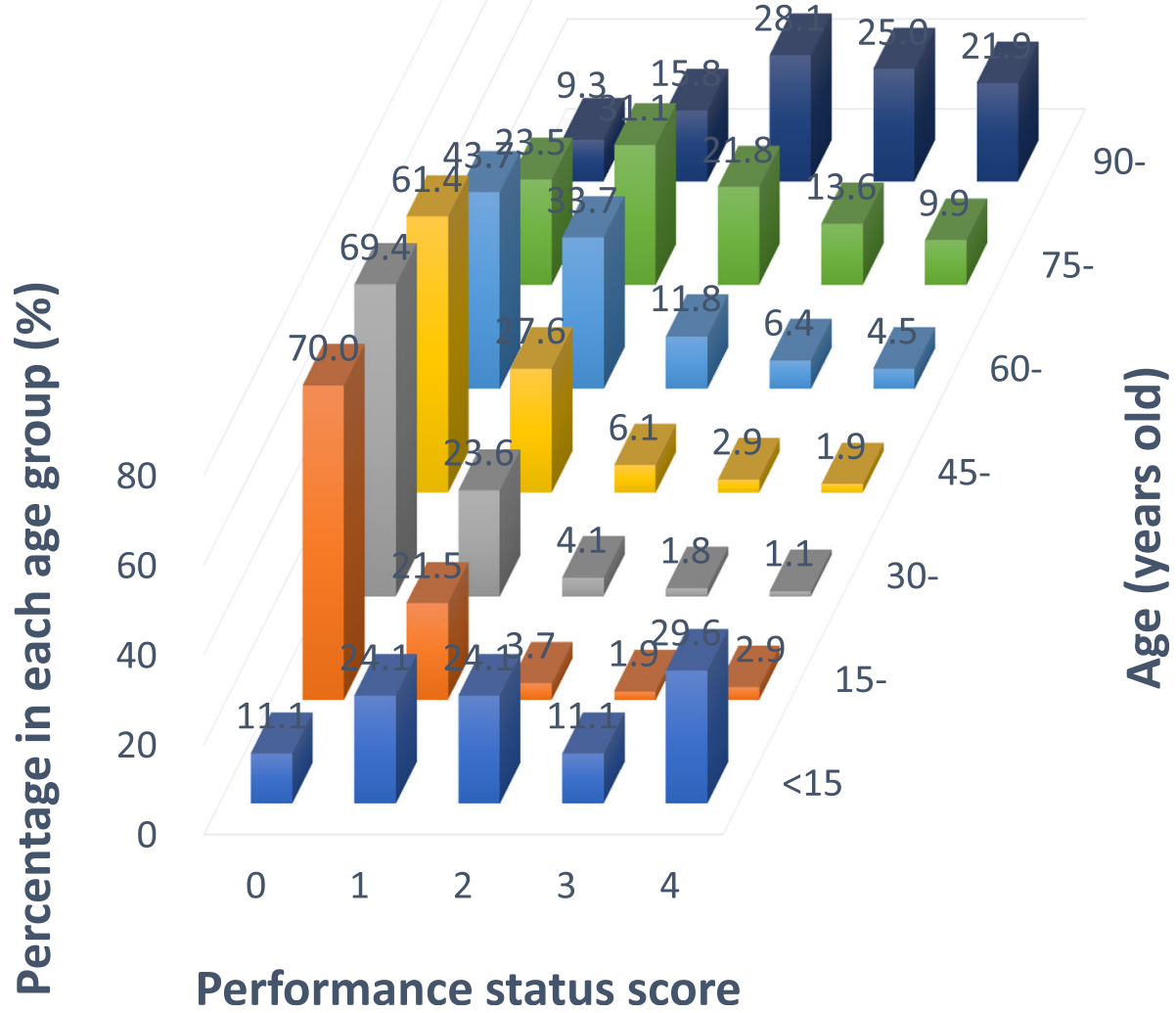

Fig. 4 Performance status and age. The numbers in the figure indicate the percentages for each age group. Data were obtained from the patient survey. 
Table 4 Performance status of patients treated by main three kinds of treatment, sorted by different age

\begin{tabular}{|c|c|c|c|c|c|c|c|c|c|}
\hline \multirow[t]{2}{*}{ Dialysis method } & \multicolumn{5}{|c|}{ Performance status score } & \multirow[t]{2}{*}{ Subtotal } & \multirow[t]{2}{*}{ Unspecified } & \multirow{2}{*}{$\begin{array}{l}\text { No data } \\
\text { available }\end{array}$} & \multirow[t]{2}{*}{ Total } \\
\hline & Score 0 & Score 1 & Score 2 & Score 3 & Score 4 & & & & \\
\hline \multicolumn{10}{|l|}{ a. Age $<20$ years old } \\
\hline Facility hemodialysis & 12 & 2 & 3 & 0 & 2 & 19 & 2 & 5 & 26 \\
\hline$\%$ & $(63.2)$ & $(10.5)$ & $(15.8)$ & $(0.0)$ & $(10.5)$ & $(100.0)$ & & & \\
\hline Hemodiafiltration & 7 & 2 & 0 & 1 & 0 & 10 & 0 & 2 & 12 \\
\hline$\%$ & $(70.0)$ & $(20.0)$ & $(0.0)$ & $(10.0)$ & $(0.0)$ & $(100.0)$ & & & \\
\hline Peritoneal dialysis & 11 & 24 & 12 & 7 & 18 & 72 & 10 & 35 & 117 \\
\hline$\%$ & $(15.3)$ & (33.3) & $(16.7)$ & $(9.7)$ & $(25.0)$ & $(100.0)$ & & & \\
\hline Total & 30 & 28 & 15 & 8 & 20 & 101 & 12 & 42 & 155 \\
\hline$\%$ & $(29.7)$ & $(27.7)$ & $(14.9)$ & $(7.9)$ & $(19.8)$ & $(100.0)$ & & & \\
\hline \multicolumn{10}{|l|}{ b. Age $20 \leq,<45$ years old } \\
\hline Facility hemodialysis & 3314 & 1197 & 224 & 106 & 87 & 4928 & 242 & 1304 & 6474 \\
\hline$\%$ & $(67.2)$ & $(24.3)$ & $(4.5)$ & $(2.2)$ & $(1.8)$ & $(100.0)$ & & & \\
\hline Hemodiafiltration & 3214 & 1017 & 172 & 63 & 26 & 4492 & 102 & 1099 & 5693 \\
\hline$\%$ & $(71.5)$ & $(22.6)$ & (3.8) & $(1.4)$ & $(0.6)$ & $(100.0)$ & & & \\
\hline Peritoneal dialysis & 274 & 89 & 7 & 6 & 6 & 382 & 34 & 238 & 654 \\
\hline$\%$ & $(71.7)$ & $(23.3)$ & $(1.8)$ & $(1.6)$ & $(1.6)$ & $(100.0)$ & & & \\
\hline Total & 6802 & 2303 & 403 & 175 & 119 & 9802 & 378 & 2641 & 12,821 \\
\hline$\%$ & $(69.4)$ & $(23.5)$ & $(4.1)$ & $(1.8)$ & $(1.2)$ & $(100.0)$ & & & \\
\hline \multicolumn{10}{|l|}{ c. Age $45 \leq,<60$ years old } \\
\hline Facility hemodialysis & 13,855 & 6543 & 1590 & 842 & 612 & 23,442 & 969 & 6010 & 30,421 \\
\hline$\%$ & $(59.1)$ & $(27.9)$ & $(6.8)$ & (3.6) & $(2.6)$ & $(100.0)$ & & & \\
\hline Hemodiafiltration & 12,594 & 5504 & 1113 & 455 & 239 & 19,905 & 500 & 5014 & 25,419 \\
\hline$\%$ & $(63.3)$ & $(27.7)$ & $(5.6)$ & $(2.3)$ & $(1.2)$ & $(100.0)$ & & & \\
\hline Peritoneal dialysis & 1018 & 358 & 48 & 11 & 13 & 1448 & 79 & 821 & 2348 \\
\hline$\%$ & $(70.3)$ & $(24.7)$ & (3.3) & $(0.8)$ & $(0.9)$ & $(100.0)$ & & & \\
\hline Total & 27,467 & 12,405 & 2751 & 1308 & 864 & 44,795 & 1548 & 11,845 & 58,188 \\
\hline$\%$ & $(61.3)$ & $(27.7)$ & $(6.1)$ & $(2.9)$ & $(1.9)$ & $(100.0)$ & & & \\
\hline \multicolumn{10}{|l|}{ d. Age $60 \leq,<75$ years old } \\
\hline Facility hemodialysis & 26,500 & 20,676 & 7809 & 4425 & 3566 & 62,976 & 2234 & 15,901 & 81,111 \\
\hline$\%$ & $(42.1)$ & $(32.8)$ & $(12.4)$ & $(7.0)$ & $(5.7)$ & $(100.0)$ & & & \\
\hline Hemodiafiltration & 18,841 & 14,599 & 4557 & 2305 & 1232 & 41,534 & 1023 & 11,136 & 53,693 \\
\hline$\%$ & $(45.4)$ & $(35.1)$ & $(11.0)$ & $(5.5)$ & (3.0) & $(100.0)$ & & & \\
\hline Peritoneal dialysis & 1396 & 680 & 171 & 55 & 48 & 2350 & 210 & 1291 & 3851 \\
\hline$\%$ & $(59.4)$ & $(28.9)$ & $(7.3)$ & $(2.3)$ & $(2.0)$ & $(100.0)$ & & & \\
\hline Total & 46,737 & 35,955 & 12,537 & 6785 & 4846 & 106,860 & 3467 & 28,328 & 138,655 \\
\hline$\%$ & $(43.7)$ & (33.6) & $(11.7)$ & $(6.3)$ & $(4.5)$ & $(100.0)$ & & & \\
\hline \multicolumn{10}{|l|}{ e. Age $75 \leq$ years old } \\
\hline Facility hemodialysis & 12,862 & 16,935 & 13,098 & 8973 & 7275 & 59,143 & 2183 & 15,121 & 76,447 \\
\hline$\%$ & $(21.7)$ & $(28.6)$ & $(22.1)$ & $(15.2)$ & $(12.3)$ & $(100.0)$ & & & \\
\hline Hemodiafiltration & 6692 & 9310 & 6252 & 3558 & 2123 & 27,935 & 730 & 8152 & 36,817 \\
\hline$\%$ & $(24.0)$ & (33.3) & $(22.4)$ & $(12.7)$ & (7.6) & $(100.0)$ & & & \\
\hline Peritoneal dialysis & 426 & 381 & 229 & 132 & 89 & 1257 & 145 & 697 & 2099 \\
\hline$\%$ & (33.9) & $(30.3)$ & $(18.2)$ & $(10.5)$ & $(7.1)$ & $(100.0)$ & & & \\
\hline
\end{tabular}


Table 4 Performance status of patients treated by main three kinds of treatment, sorted by different age (Continued)

\begin{tabular}{|c|c|c|c|c|c|c|c|c|c|}
\hline \multirow[t]{2}{*}{ Dialysis method } & \multicolumn{5}{|c|}{ Performance status score } & \multirow[t]{2}{*}{ Subtotal } & \multirow[t]{2}{*}{ Unspecified } & \multirow{2}{*}{$\begin{array}{l}\text { No data } \\
\text { available }\end{array}$} & \multirow[t]{2}{*}{ Total } \\
\hline & Score 0 & Score 1 & Score 2 & Score 3 & Score 4 & & & & \\
\hline Total & 19,980 & 26,626 & 19,579 & 12,663 & 9487 & 88,335 & 3058 & 23,970 & 115,363 \\
\hline$\%$ & $(22.6)$ & (30.1) & $(22.2)$ & $(14.3)$ & (10.7) & $(100.0)$ & & & \\
\hline
\end{tabular}

The data were obtained from the patient survey

following 7 answer choices in response to a question regarding exercise habits.
A. Not at all or hardly
B. Less than once a week
C. Almost once a week
D. Two or three times a week
E. Four or five times a week
F. Every day or nearly every day
Z. Unknown

In the current survey, an answer to the question regarding exercise habits was collected from 213,930 patients $(65.4 \%)$.

\section{Results \\ Presence/absence of dementia \\ Age and dementia prevalence}

The prevalence of dementia was calculated among all the dialysis patients and in each of the major age groups. The

Table $\mathbf{5}$ The prevalence of dementia sorted by age and performance status

\begin{tabular}{|c|c|c|c|c|c|c|c|c|c|}
\hline \multirow{2}{*}{$\begin{array}{l}\text { Presence/absence of } \\
\text { dementia }\end{array}$} & \multicolumn{5}{|c|}{ Performance status score } & \multirow[t]{2}{*}{ Subtotal } & \multirow[t]{2}{*}{ Unspecified } & \multirow{2}{*}{$\begin{array}{l}\text { No data } \\
\text { available }\end{array}$} & \multirow[t]{2}{*}{ Total } \\
\hline & Score 0 & Score 1 & Score 2 & Score 3 & Score 4 & & & & \\
\hline \multicolumn{10}{|l|}{ a. Age $<65$ years old } \\
\hline Without dementia & 46,015 & 21,848 & 4885 & 2292 & 1283 & 76,323 & 1233 & 1783 & 79,339 \\
\hline With dementia & 289 & 278 & 226 & 235 & 348 & 1376 & 37 & 39 & 1452 \\
\hline Subtotal & 46,304 & 22,126 & 5111 & 2527 & 1631 & 77,699 & 1270 & 1,822 & 80,791 \\
\hline Unspecified & 592 & 481 & 161 & 94 & 175 & 1503 & 1462 & 2893 & 5858 \\
\hline No data available & 1008 & 517 & 127 & 80 & 38 & 1,770 & 54 & 16,754 & 18,578 \\
\hline Total & 47,904 & 23,124 & 5399 & 2701 & 1844 & 80,972 & 2786 & 21,469 & 105,227 \\
\hline Dementia prevalence (\%) & 0.6 & 1.3 & 4.4 & 9.3 & 21.3 & 1.8 & 2.9 & 2.1 & 1.8 \\
\hline \multicolumn{10}{|l|}{ b. Age $65 \leq,<75$ years old } \\
\hline Without dementia & 32,132 & 25,876 & 8703 & 4218 & 2211 & 73,140 & 1120 & 1624 & 75,884 \\
\hline With dementia & 519 & 953 & 1158 & 1100 & 1472 & 5202 & 116 & 185 & 5503 \\
\hline Subtotal & 32,651 & 26,829 & 9861 & 5318 & 3683 & 78,342 & 1236 & 1809 & 81,387 \\
\hline Unspecified & 460 & 530 & 336 & 196 & 262 & 1784 & 1351 & 2998 & 6133 \\
\hline No data available & 767 & 648 & 260 & 130 & 86 & 1891 & 57 & 16,914 & 18,862 \\
\hline Total & 33,878 & 28,007 & 10,457 & 5644 & 4031 & 82,017 & 2644 & 21,721 & 106,382 \\
\hline Dementia prevalence (\%) & 1.6 & 3.6 & 11.7 & 20.7 & 40.0 & 6.6 & 9.4 & 10.2 & 6.8 \\
\hline \multicolumn{10}{|l|}{ c. Age $75 \leq$ years old } \\
\hline Without dementia & 18,242 & 22,867 & 13,660 & 7186 & 3305 & 65,260 & 1101 & 1571 & 67,932 \\
\hline With dementia & 1030 & 2613 & 4918 & 4814 & 5551 & 18,926 & 371 & 635 & 19,932 \\
\hline Subtotal & 19,272 & 25,480 & 18,578 & 12,000 & 8856 & 84,186 & 1472 & 2206 & 87,864 \\
\hline Unspecified & 339 & 635 & 603 & 449 & 475 & 2501 & 1544 & 3242 & 7287 \\
\hline No data available & 429 & 611 & 480 & 244 & 169 & 1933 & 50 & 18,593 & 20,576 \\
\hline Total & 20,040 & 26,726 & 19,661 & 12,693 & 9,500 & 88,620 & 3,066 & 24,041 & 115,727 \\
\hline Dementia prevalence (\%) & 5.3 & 10.3 & 26.5 & 40.1 & 62.7 & 22.5 & 25.2 & 28.8 & 22.7 \\
\hline
\end{tabular}

The data were obtained from the patient survey 
results are shown in Table 2 . The overall dementia prevalence among dialysis patients in the 2018 survey was $10.8 \%$ (1.8\% in the age group of less than 65 years, $6.8 \%$ in the age group of $65-74$ years, and $22.7 \%$ in the age group of 75 years or older). Thus, the dementia prevalence was markedly higher among subjects older than 65 years.

\section{Sex and dementia prevalence}

Figure 1 shows the dementia prevalence in each of the major age groups calculated according to sex. In each age group, the dementia prevalence was higher among females than among males (Supplementary Table 1).

\section{Presence/absence of diabetes mellitus and dementia prevalence}

Figure 2 shows the relationship between the presence/absence of diabetes mellitus and the dementia prevalence (Supplementary Table 2). In each age group, the dementia prevalence was higher among diabetic patients than among non-diabetic patients.

\section{Treatment method and dementia prevalence}

Table 3 shows the relationship between the three main treatment methods (facility hemodialysis, hemodiafiltration, and peritoneal dialysis) and the dementia prevalence. Hemodialysis patients had the highest prevalence of dementia, followed by hemodiafiltration patients and peritoneal dialysis patients.

\section{Dialysis vintage and dementia prevalence}

Figure 3 shows the relationship between the dialysis vintage and the dementia prevalence. During the first 10 years of dialysis, the dementia prevalence increased as the dialysis vintage increased (Supplementary Table 3). After 10 years, however, the dementia prevalence decreased as the dialysis vintage increased.

\section{Performance status (PS) \\ Age and PS}

Figure 4 graphically represents the distribution of age and PS (Supplementary Table 4). The percentages of patients with lower activity levels (higher PS scores) were relatively high among patients who were less than 15 years old or 60 years or older. Among patients who were 90 years or

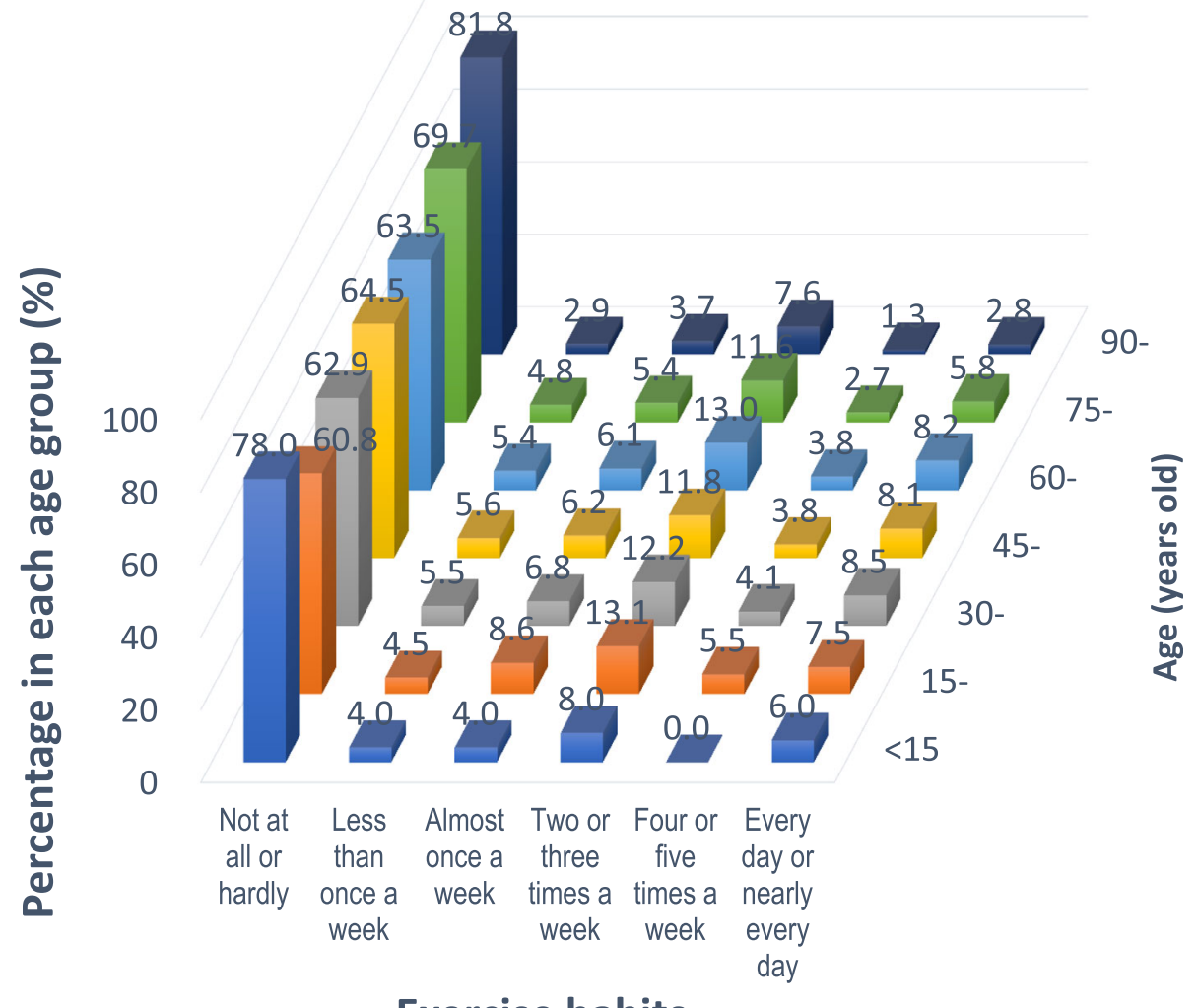

Exercise habits

Fig. 5 Exercise habits and age. The numbers in the figure indicate the percentages for each age group. Data were obtained from the patient survey 
older, the overwhelming majority of patients had low activity levels (high PS scores), and the percentage of patients with high activity levels (low PS scores) was small.

\section{Treatment method and PS}

Table 4 shows the relationship between the main three treatment methods (facility hemodialysis, hemodiafiltration, and peritoneal dialysis) and PS. The number of patients tabulated in some cells was too small, so this tabulation was performed as "under 20 years old" instead of "under 15 years old." Among patients aged 20 years or older, patients treated by peritoneal dialysis were the most active, followed by those treated with hemodiafiltration and facility hemodialysis. Among patients under the age of 20 years, patients treated by hemodiafiltration were the most active, followed by those treated with facility hemodialysis and peritoneal dialysis.

\section{Dementia prevalence and PS}

Table 5 shows the results summarizing the relationship between the prevalence of dementia and PS according to different age groups. Regardless of age, patients with a lower activity have a higher prevalence of dementia.

\section{Exercise habits \\ Age and exercise habits}

Figure 5 shows the results of the analysis of age versus exercise habits among the dialysis patients (Supplementary Table 5). In each age group, patients who were classified as "Not at all or hardly" in response to the question on exercise habits were predominant, accounting for $60-80 \%$ of all the patients.

\section{Dialysis vintage and exercise habits}

Next, the patients were divided into four age groups $(0-$ $44,45-64,65-74$, and 75 years or older), and the relationship between the dialysis vintage and exercise habits was analyzed in each age group (Figs. 6, 7, 8 and 9; Supplementary Table 6). In the 45 years and older age groups, the percentages of patients who were classified as "Not at all or hardly" tended to be higher when the dialysis vintage was 35 years or longer. In the $0-44$ age groups, the percentage of patients who were classified as "Not at all or

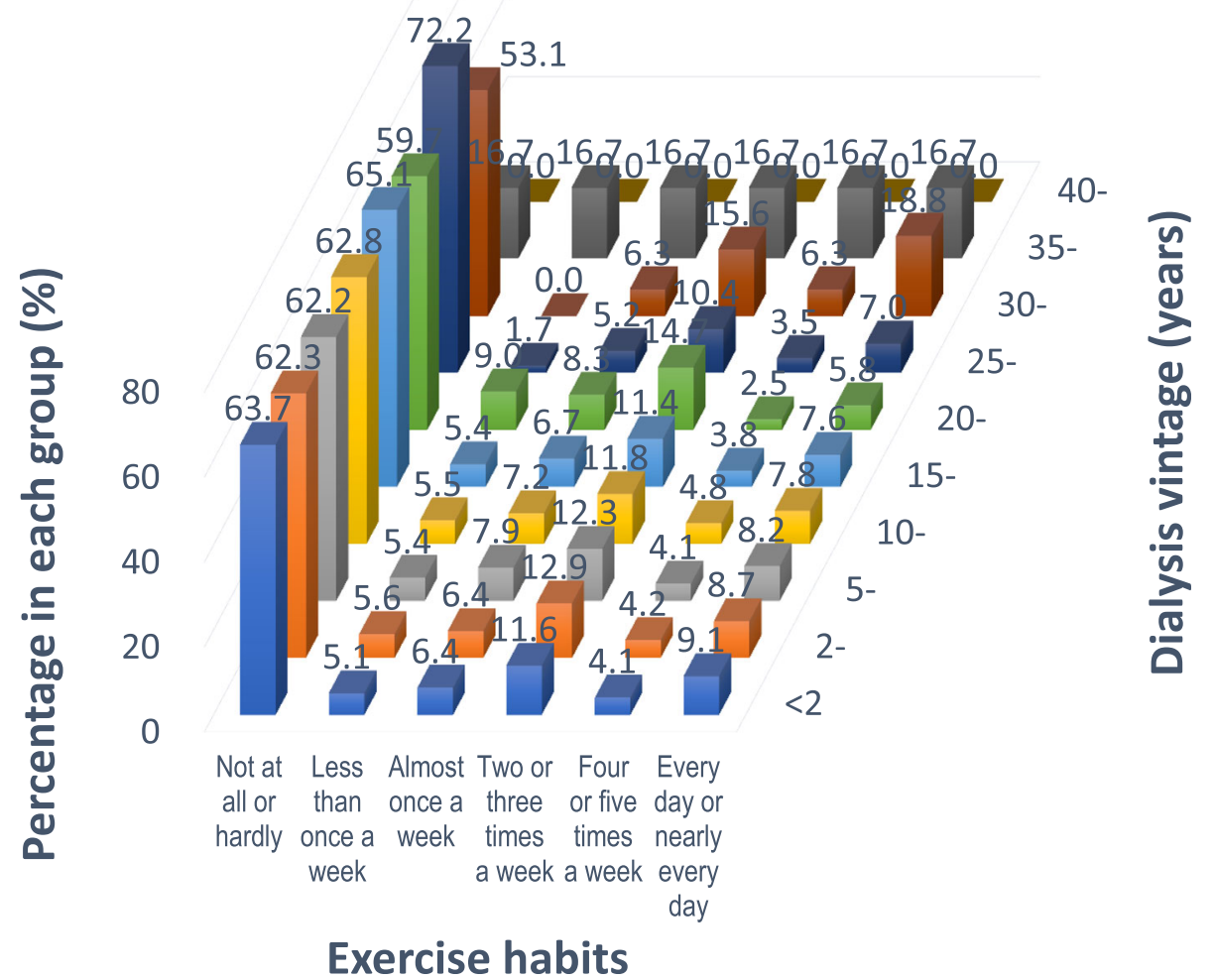

Fig. 6 Exercise habits and dialysis vintage: under 45 years old. The numbers in the figure indicate the percentages for each dialysis vintage group. Data were obtained from the patient survey 
hardly" tended to increase in the group with a dialysis vintage of 25-29 years. However, the age 0-44 age groups included almost no patients with a dialysis vintage of 35 years or longer. No other evident relationship between the duration vintage and exercise habits was seen.

\section{PS and exercise habits}

Table 6 shows the results summarizing the relationship between exercise habits and PS for all the patients. Patients who exercised more often had a higher physical activity.

\section{Dementia prevalence and exercise habits}

Table 7 shows the results of tabulating the relationship between exercise habits and the prevalence of dementia according to major age group. Patients who exercised more frequently had a lower prevalence of dementia across all age groups.

\section{Discussion}

Presence/absence of dementia

Age and dementia prevalence

When the prevalence of dementia was analyzed in each of the major age groups, the dementia prevalence was found to be markedly increased in the 65 years or older age group (Table 2). As reference data, Fig. 10 shows the changes in dementia prevalence over time for each of the major age groups in the 2009, 2010, and 2018 surveys (Supplementary Table 7). The analyses in the 2009 and 2010 surveys were confined to "patients receiving hemodialysis at a facility 3 times/week" $[8,9]$. For this reason, the analysis in 2018 included only "patients receiving hemodialysis at facilities 3 times/week." The dementia prevalence in 2018 in each age group was approximately equal to the corresponding prevalence recorded in 2009 and 2010. This indicates that the status of dementia prevalence among dialysis patients in Japan has not changed markedly over the past decade.

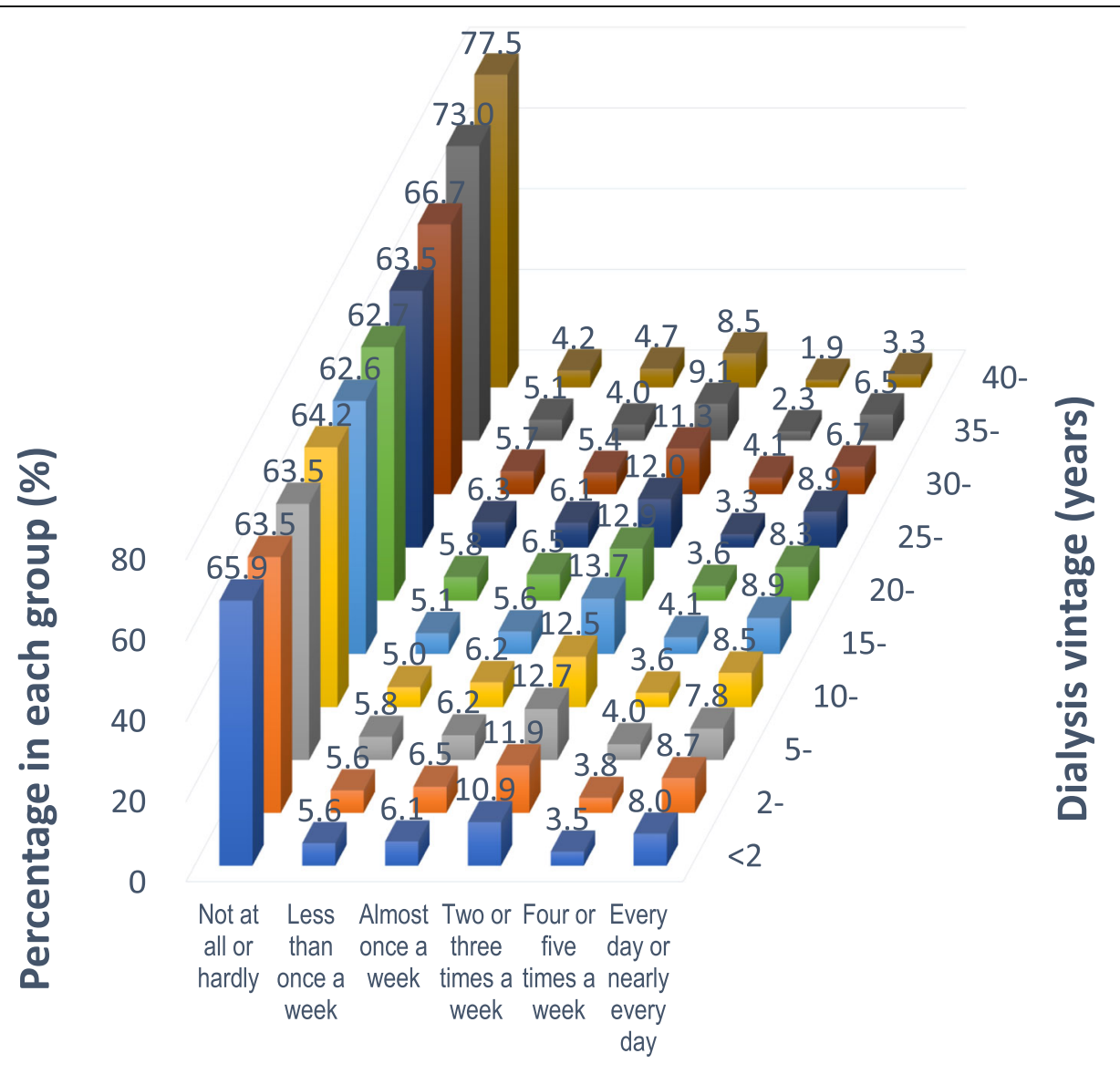

\section{Exercise habits}

Fig. 7 Exercise habits and dialysis vintage: 45-64 years old. The numbers in the figure indicate the percentages for each dialysis vintage group. Data were obtained from the patient survey 


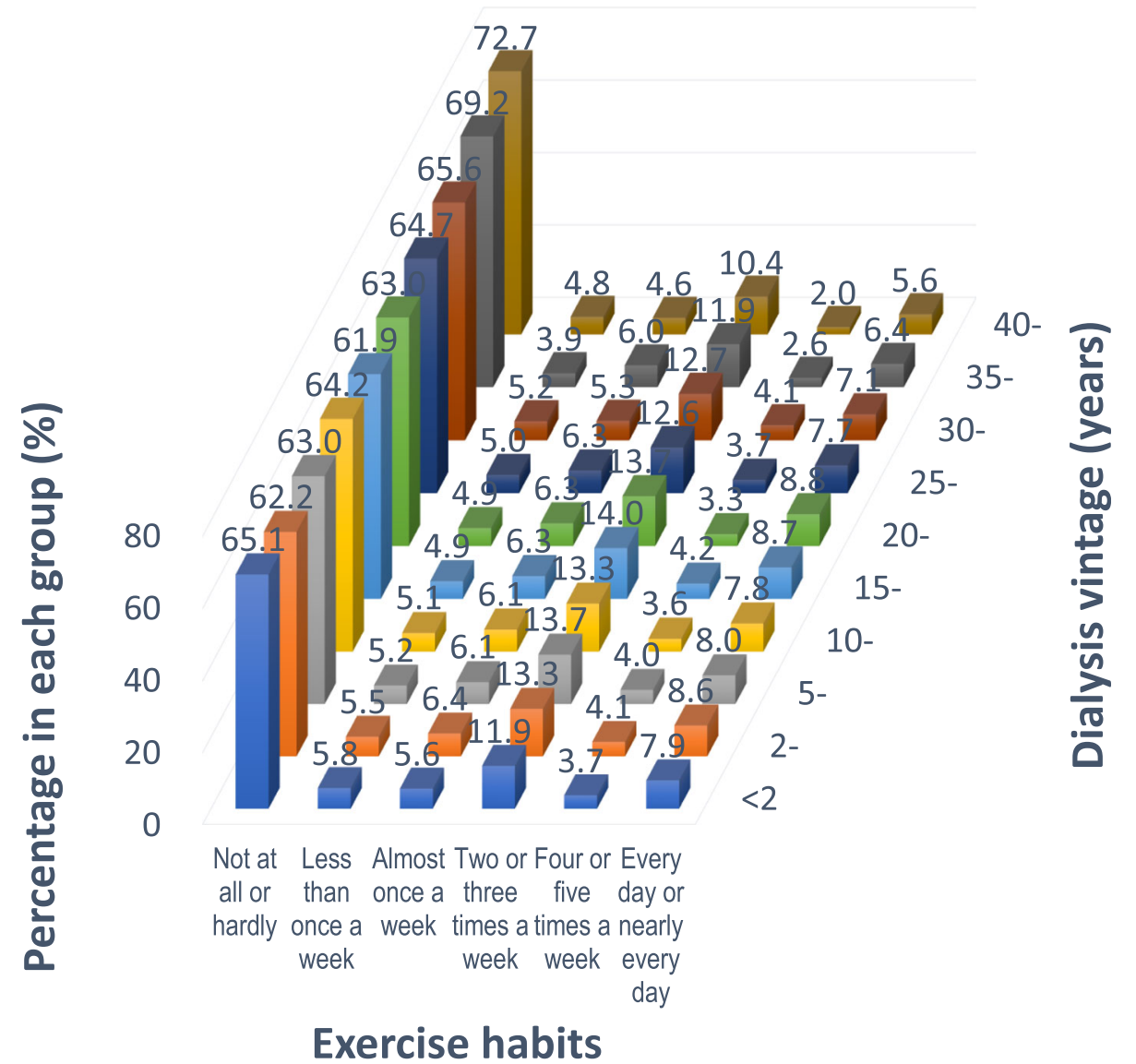

Fig. 8 Exercise habits and dialysis vintage: 65-74 years old. The numbers in the figure indicate the percentages for each dialysis vintage group. Data were obtained from the patient survey

\section{Sex and dementia prevalence}

When the dementia prevalence in each of the major age groups was analyzed according to sex, the prevalence in each age group was higher in the females than in the males (Fig. 1). A similar trend to that noted in the current survey was also observed in the surveys conducted in 2009 and 2010 within the framework of this survey program $[8,9]$. Among elderly patients, the prevalence of dementia is generally higher in females than in males [14]. On the other hand, in Japan, the prevalence of dementia among young people under the age of 65 years has been reported to be lower in females than in males [15]. However, in this report, the prevalence of dementia in dialysis patients under the age of 65 years was higher in females than in males. To explore this matter, the prevalence of dementia according to the presence or absence of diabetes and the dialysis vintage was calculated for each sex (Tables 8 and 9). As shown here, the prevalence of dementia calculated for each age group was higher in females than in males, regardless of the presence of diabetes or the dialysis vintage. These results indicate that among Japanese dialysis patients, females are more susceptible to dementia than males. We could not clarify the reason for this difference in the present analysis.

\section{Presence/absence of diabetes mellitus and dementia prevalence}

An analysis of the relationship between the presence/absence of diabetes mellitus and the dementia prevalence revealed that the dementia prevalence was higher among diabetic patients than among non-diabetic patients in each age group (Fig. 2). This result was consistent with the previously reported finding that diabetes mellitus is a risk factor for dementia [16]. A trend similar to that observed in the current survey was also noted in the surveys conducted in 2009 and 2010 within the framework of this survey program $[8,9]$.

\section{Treatment method and dementia prevalence}

As shown in Table 3, facility hemodialysis patients had the highest prevalence of dementia, followed by 


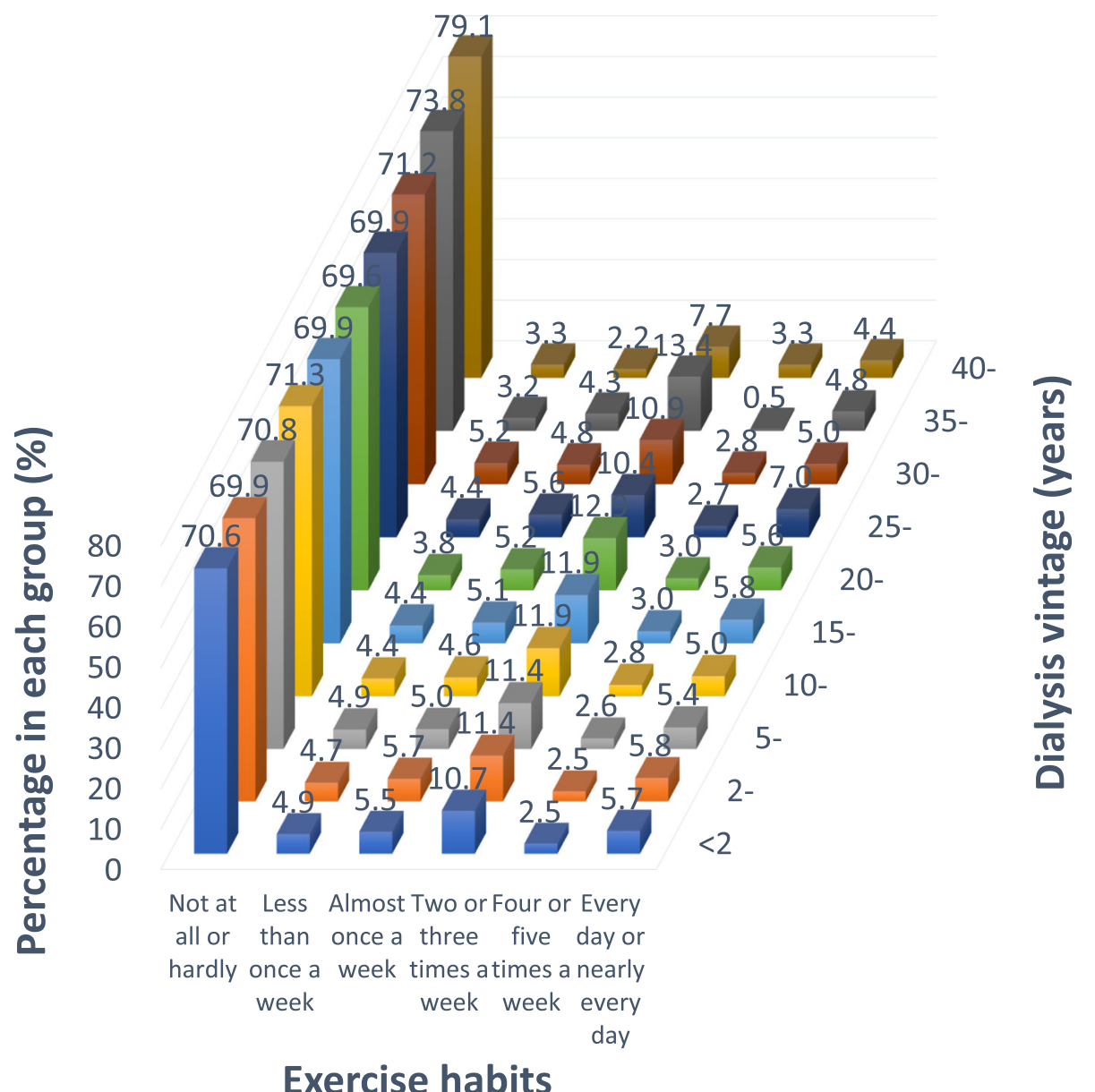

Fig. 9 Exercise habits and dialysis vintage: 75 years or older. The numbers in the figure indicate the percentages for each dialysis vintage group. Data were obtained from the patient survey

hemodiafiltration patients and peritoneal dialysis patients, regardless of age. Table 10 shows the basic background factors of the patients who were treated with each of the three main treatment methods. The mean age of the facility hemodialysis patients was the highest, followed by the mean ages of the hemodiafiltration and peritoneal dialysis patients. However, the prevalence of dementia, shown in Table 3, had already been stratified according to the different age groups. Therefore, it is difficult to attribute the high prevalence of dementia in facility hemodialysis patients to their advanced age. The mean dialysis vintage was the longest for hemodiafiltration, followed by those for facility hemodialysis and peritoneal dialysis. There was no significant difference in the percentage of male patients receiving each treatment. Thus, it seems unlikely that these findings could have affected the high prevalence of dementia among facility hemodialysis patients. The prevalence of diabetes was highest among facility hemodialysis patients, followed by patients receiving hemodiafiltration and peritoneal dialysis. This report shows that patients with diabetes have a high prevalence of dementia. This may have affected the high prevalence of dementia among facility hemodialysis patients and the low prevalence of dementia among peritoneal dialysis patients.

\section{Dialysis vintage and dementia prevalence}

In an analysis of the relationship between the duration of dialysis and the dementia prevalence, the dementia prevalence increased as the dialysis vintage increased in patients whose dialysis vintage was less than 10 years. Among patients whose dialysis vintage was more than 10 years, however, the dementia prevalence decreased as the dialysis vintage increased (Fig. 3 ). A trend similar to the one observed in the current survey was also noted in the surveys conducted in 2009 and 2010 within the framework of this survey program $[8,9]$. To clarify this background, the relationships between dialysis vintage and basic background factors are summarized in Table 11 . No significant difference in the mean age of patients belonging to each dialysis vintage was seen for patients with a dialysis vintage of less than 10 years, but the mean age tended to be lower in patients with a long dialysis vintage among 
Table 6 Exercise habits and performance status (all dialysis patients)

\begin{tabular}{|c|c|c|c|c|c|c|c|c|c|}
\hline \multirow[t]{2}{*}{ Exercise habits } & \multicolumn{5}{|c|}{ Performance status score } & \multirow[t]{2}{*}{ Subtotal } & \multirow[t]{2}{*}{ Unspecified } & \multirow{2}{*}{$\begin{array}{l}\text { No data } \\
\text { available }\end{array}$} & \multirow[t]{2}{*}{ Total } \\
\hline & Score 0 & Score 1 & Score 2 & Score 3 & Score 4 & & & & \\
\hline Not at all or hardly & 48,347 & 40,194 & 22,863 & 15,643 & 13,161 & 140,208 & 781 & 576 & 141,565 \\
\hline$\%$ & $(34.5)$ & $(28.7)$ & $(16.3)$ & $(11.2)$ & $(9.4)$ & $(100.0)$ & & & \\
\hline Less than once a week & 4522 & 4282 & 1596 & 479 & 139 & 11,018 & 13 & 10 & 11,041 \\
\hline$\%$ & $(41.0)$ & (38.9) & $(14.5)$ & $(4.3)$ & $(1.3)$ & $(100.0)$ & & & \\
\hline Almost once a week & 5315 & 4541 & 1769 & 648 & 172 & 12,445 & 35 & 20 & 12,500 \\
\hline$\%$ & $(42.7)$ & $(36.5)$ & $(14.2)$ & $(5.2)$ & $(1.4)$ & $(100.0)$ & & & \\
\hline Two or three times a week & 11,325 & 9262 & 3256 & 1457 & 497 & 25,797 & 43 & 197 & 26,037 \\
\hline$\%$ & $(43.9)$ & $(35.9)$ & $(12.6)$ & $(5.6)$ & $(1.9)$ & $(100.0)$ & & & \\
\hline Four or five times a week & 3975 & 2472 & 483 & 167 & 98 & 7195 & 7 & 33 & 7235 \\
\hline$\%$ & $(55.2)$ & $(34.4)$ & $(6.7)$ & $(2.3)$ & $(1.4)$ & $(100.0)$ & & & \\
\hline Every day or nearly every day & 9398 & 4699 & 969 & 275 & 86 & 15,427 & 21 & 104 & 15,552 \\
\hline$\%$ & $(60.9)$ & $(30.5)$ & $(6.3)$ & $(1.8)$ & $(0.6)$ & $(100.0)$ & & & \\
\hline Subtotal & 82,882 & 65,450 & 30,936 & 18,669 & 14,153 & 212,090 & 900 & 940 & 213,930 \\
\hline$\%$ & $(39.1)$ & $(30.9)$ & $(14.6)$ & $(8.8)$ & $(6.7)$ & $(100.0)$ & & & \\
\hline Unspecified & 16,455 & 10,356 & 3730 & 2012 & 1010 & 33,563 & 7507 & 718 & 41,788 \\
\hline No data available & 2485 & 2051 & 851 & 357 & 212 & 5956 & 89 & 65,573 & 71,618 \\
\hline Total & 101,822 & 77,857 & 35,517 & 21,038 & 15,375 & 251,609 & 8496 & 67,231 & 327,336 \\
\hline$\%$ & $(40.5)$ & (30.9) & (14.1) & (8.4) & (6.1) & $(100.0)$ & & & \\
\hline
\end{tabular}

The data were obtained from the patient survey

patients with a dialysis vintage of 10 years or more. In addition, a small proportion of patients with a dialysis vintage of 10 years or more had diabetes. This tendency was remarkable among patients with a dialysis vintage of 20 years or more. Thus, patients with diabetes had a relatively high prevalence of dementia in this tabulation. This may have been associated with the low prevalence of dementia among patients with a long dialysis vintage. It was previously reported that in non-diabetic patients with no history of cerebrovascular disease undergoing maintenance hemodialysis, the risk of the onset of dementia decreased as the dialysis vintage increased [17]. The results of the current survey may be consistent with this previous report.

\section{Performance status (PS) \\ Age and PS}

When the PS was analyzed according to age, the percentage of patients with lower activity levels (larger PS scores) increased in the 75 years or older age group. In the 65-74 years age group, on the other hand, the distribution of the PS scores was close to that in the 45-59 years age group. This result may indicate that the physical activity level in dialysis patients is relatively well preserved until the age of 75 years but begins to decrease rapidly after the age of 75 years. On the other hand, there were many patients with low activity scores in the under 15-year-old age group. This finding may indicate that renal failure impedes the development of the patients' physical functions.

Figures 11, 12, and 13 show the distribution of the PS scores in each of the major age groups evaluated at 3 points of time $(1998,2009$, and 2018) [8, 12]. The data for 1998 and 2018 cover all the dialysis patients, while the data for 2009 covers only those patients who were receiving hemodialysis at a facility 3 times/week. During the period from 1998 to 2009, the percentage of patients with high activity levels increased slightly and that of patients with low activity levels decreased slightly in each age group (note that a small PS score means a high activity level). However, during the period from 2009 to 2018, the percentage of patients with high activity levels decreased and that of patients with low activity levels increased slightly in the 75 years or older age group. This may indicate that the physical activity level in the dialysis patients tended to improve from 1998 to 2009, but has improved minimally thereafter.

\section{Treatment method and PS}

As shown in Table 4, among patients aged 20 years and older, the PS of peritoneal dialysis patients was better than those of hemodiafiltration and facility hemodialysis patients. The number of patients tabulated in some cells was too small, so this tabulation 
Table 7 Exercise habits and the prevalence of dementia, sorted by different age

\begin{tabular}{|c|c|c|c|c|c|c|c|}
\hline \multirow[t]{2}{*}{ Exercise habits } & \multicolumn{2}{|c|}{ Presence/absence of dementia } & \multirow[t]{2}{*}{ Subtotal } & \multirow[t]{2}{*}{ Unspecified } & \multirow{2}{*}{$\begin{array}{l}\text { No data } \\
\text { available }\end{array}$} & \multirow[t]{2}{*}{ Total } & \multirow{2}{*}{$\begin{array}{l}\text { Dementia } \\
\text { prevalence } \\
\text { (\%) }\end{array}$} \\
\hline & Without dementia & With dementia & & & & & \\
\hline \multicolumn{8}{|l|}{ a. Age $<65$ years old } \\
\hline Not at all or hardly & 40,525 & 933 & 41,458 & 754 & 939 & 43,151 & 2.3 \\
\hline Less than once a week & 3571 & 51 & 3622 & 81 & 37 & 3740 & 1.4 \\
\hline Almost once a week & 4007 & 92 & 4099 & 57 & 54 & 4210 & 2.2 \\
\hline Two or three times a week & 7686 & 123 & 7809 & 137 & 233 & 8179 & 1.6 \\
\hline Four or five times a week & 2450 & 22 & 2472 & 31 & 46 & 2549 & 0.9 \\
\hline Every day or nearly every day & 5342 & 42 & 5384 & 84 & 107 & 5575 & 0.8 \\
\hline Subtotal & 63,581 & 1263 & 64,844 & 1144 & 1416 & 67,404 & 1.9 \\
\hline Unspecified & 12,753 & 139 & 12,892 & 1827 & 349 & 15,068 & 1.1 \\
\hline No data available & 3005 & 50 & 3055 & 2887 & 16,813 & 22,755 & 1.6 \\
\hline Total & 79,339 & 1452 & 80,791 & 5858 & 18,578 & 105,227 & 1.8 \\
\hline \multicolumn{8}{|l|}{ b. Age $65 \leq,<75$ years old } \\
\hline Not at all or hardly & 38,775 & 3786 & 42,561 & 890 & 900 & 44,351 & 8.9 \\
\hline Less than once a week & 3404 & 157 & 3561 & 102 & 37 & 3700 & 4.4 \\
\hline Almost once a week & 3907 & 220 & 4127 & 63 & 52 & 4242 & 5.3 \\
\hline Two or three times a week & 8348 & 408 & 8756 & 177 & 249 & 9182 & 4.7 \\
\hline Four or five times a week & 2520 & 57 & 2577 & 45 & 60 & 2682 & 2.2 \\
\hline Every day or nearly every day & 5326 & 133 & 5459 & 103 & 119 & 5681 & 2.4 \\
\hline Subtotal & 62,280 & 4761 & 67,041 & 1380 & 1417 & 69,838 & 7.1 \\
\hline Unspecified & 10,796 & 467 & 11,263 & 1765 & 351 & 13,379 & 4.1 \\
\hline No data available & 2808 & 275 & 3083 & 2988 & 17,094 & 23,165 & 8.9 \\
\hline Total & 75,884 & 5503 & 81,387 & 6133 & 18,862 & 106,382 & 6.8 \\
\hline \multicolumn{8}{|l|}{ c. Age $75 \leq$ years old } \\
\hline Not at all or hardly & 37,285 & 14,275 & 51,560 & 1480 & 1023 & 54,063 & 27.7 \\
\hline Less than once a week & 2952 & 518 & 3470 & 93 & 38 & 3601 & 14.9 \\
\hline Almost once a week & 3330 & 590 & 3920 & 80 & 48 & 4048 & 15.1 \\
\hline Two or three times a week & 6992 & 1257 & 8249 & 208 & 219 & 8676 & 15.2 \\
\hline Four or five times a week & 1740 & 183 & 1923 & 41 & 40 & 2004 & 9.5 \\
\hline Every day or nearly every day & 3703 & 401 & 4104 & 111 & 81 & 4296 & 9.8 \\
\hline Subtotal & 56,002 & 17,224 & 73,226 & 2013 & 1449 & 76,688 & 23.5 \\
\hline Unspecified & 9273 & 1762 & 11,035 & 2038 & 268 & 13,341 & 16.0 \\
\hline No data available & 2657 & 946 & 3603 & 3236 & 18,859 & 25,698 & 26.3 \\
\hline Total & 67,932 & 19,932 & 87,864 & 7287 & 20,576 & 115,727 & 22.7 \\
\hline
\end{tabular}

The data were obtained from the patient survey

was performed as "under 20 years old" instead of "under 15 years old." This table may indicate that highly active patients are more likely to choose peritoneal dialysis. On the other hand, among patients under the age of 20 years, most of the patients chose peritoneal dialysis, and several peritoneal dialysis patients had low activity levels. These results suggest that pediatric renal failure patients tend to choose peritoneal dialysis and that their physical activity level is relatively low.

\section{Dementia prevalence and PS}

As shown in Table 5, regardless of age, patients with lower activity levels had a higher prevalence of dementia. Previous studies have shown that physical activity prevents the onset of dementia $[18,19]$. The result of this 


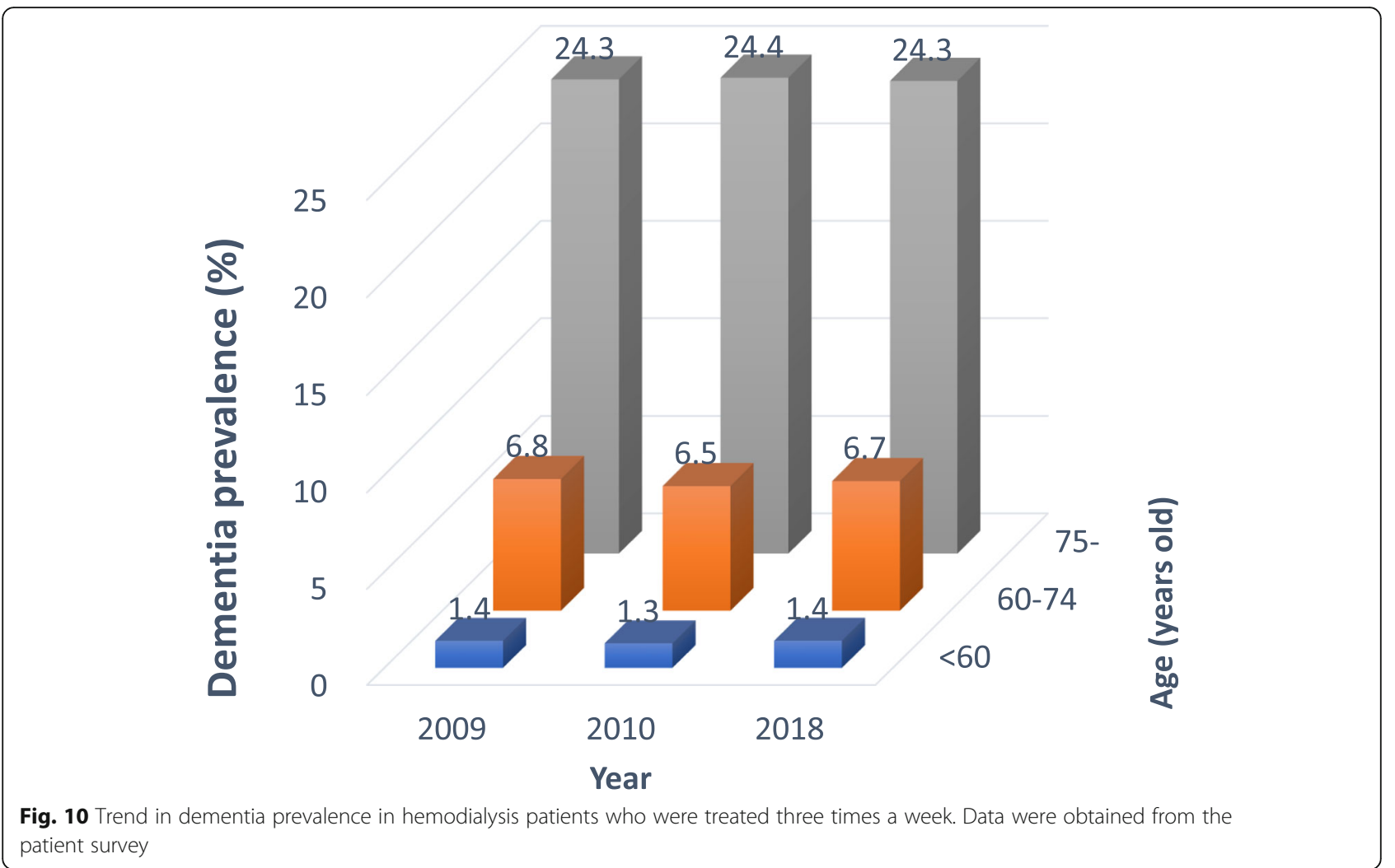

report is consistent with the results of these previous studies.

\section{Exercise habits}

\section{Age and exercise habits}

When exercise habits were analyzed according to age, the answer "Not at all or hardly" was predominantly selected in each age group (Fig. 9). The next most frequently selected choice was "Two or three times a week" $(8-13 \%)$ in each age group. This may indicate that the patients exercised at a pace consistent with a schedule in which hemodialysis was performed three times weekly. The percentages of patients who were classified as "Almost once a week" and "Every day or nearly every day" were each $4-8 \%$ in each age group.

\section{Dialysis vintage and exercise habits}

When the exercise habits were analyzed according to dialysis vintage (Figs. 7, 8, and 9), the percentage of patients who were classified as "Not at all or hardly" tended to be relatively high in the patients with a long dialysis vintage in each age group. This finding suggests that some patients receiving prolonged hemodialysis might have developed a motor disorder.

\section{PS and exercise habits}

As shown in Table 6, patients who exercised more often had higher physical activities. However, these results represent single observations made at one time point. Therefore, the causal relationship between exercise habits and physical activity cannot be discussed based on these results. However, this result indicates that exercise habits and physical activity are closely related even in dialysis patients.

\section{Dementia prevalence and exercise habits}

As shown in Table 7, patients who exercised more frequently had a lower prevalence of dementia across all age groups. Previous studies have shown that physical exercise prevents the onset of dementia [18, 19]. This result is consistent with the results of these previous studies. However, the present results represent observations made at a single point in time. Therefore, the causal relationship between exercise habits and dementia prevalence cannot be discussed based on these results.

\section{Conclusion}

In the 2018 survey, the presence/absence of dementia, PS, and exercise habits was investigated in individual 


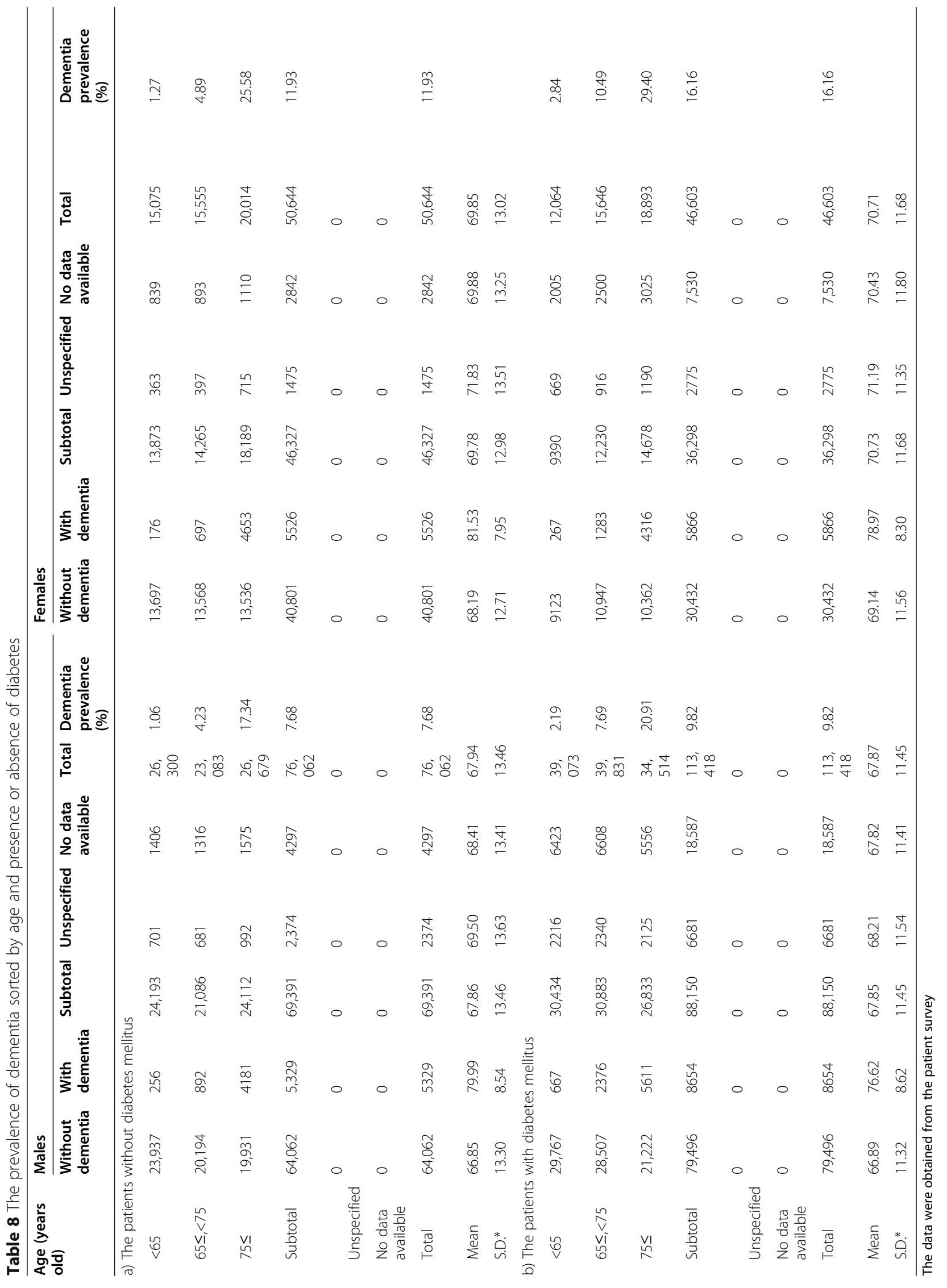




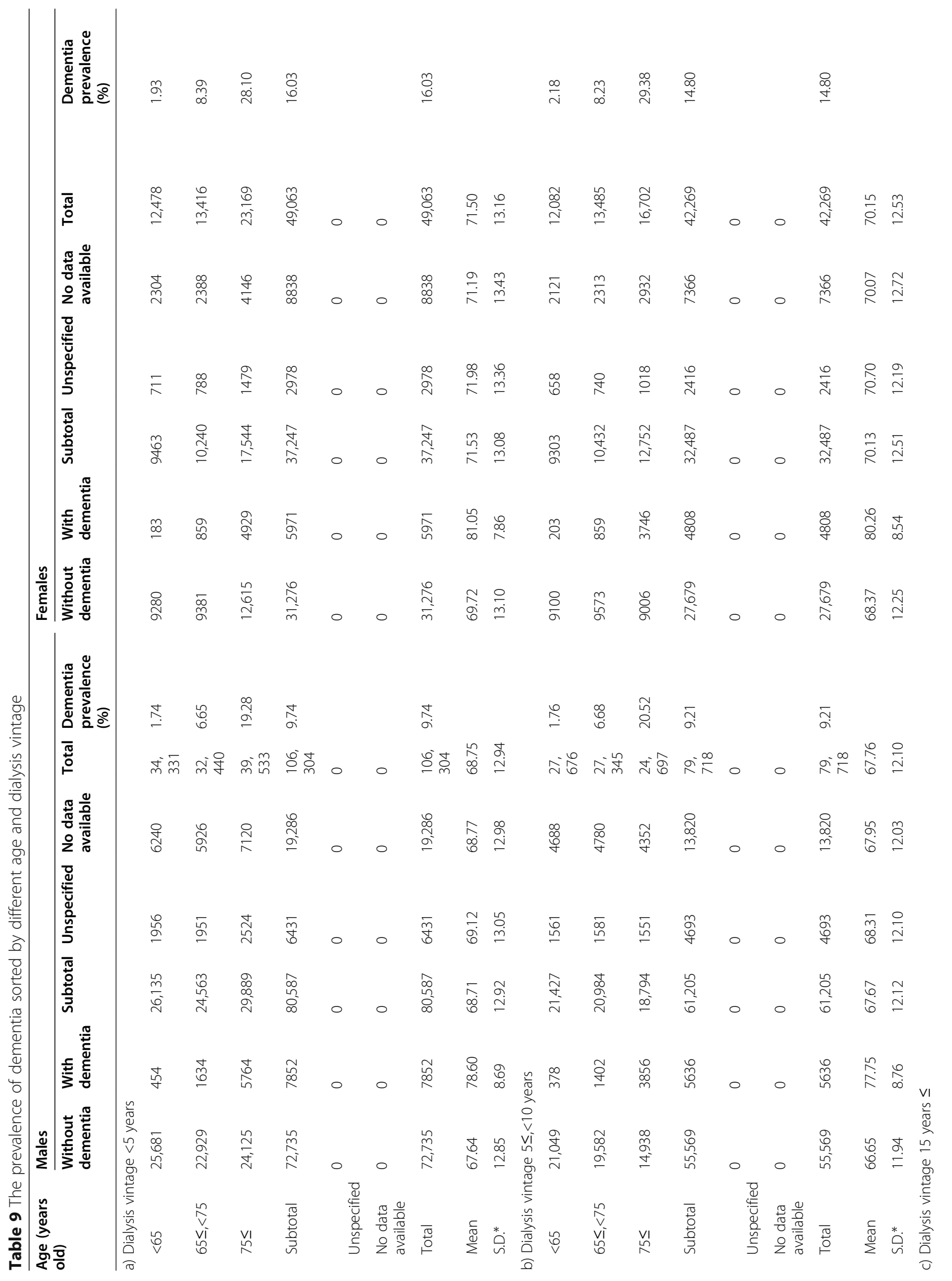




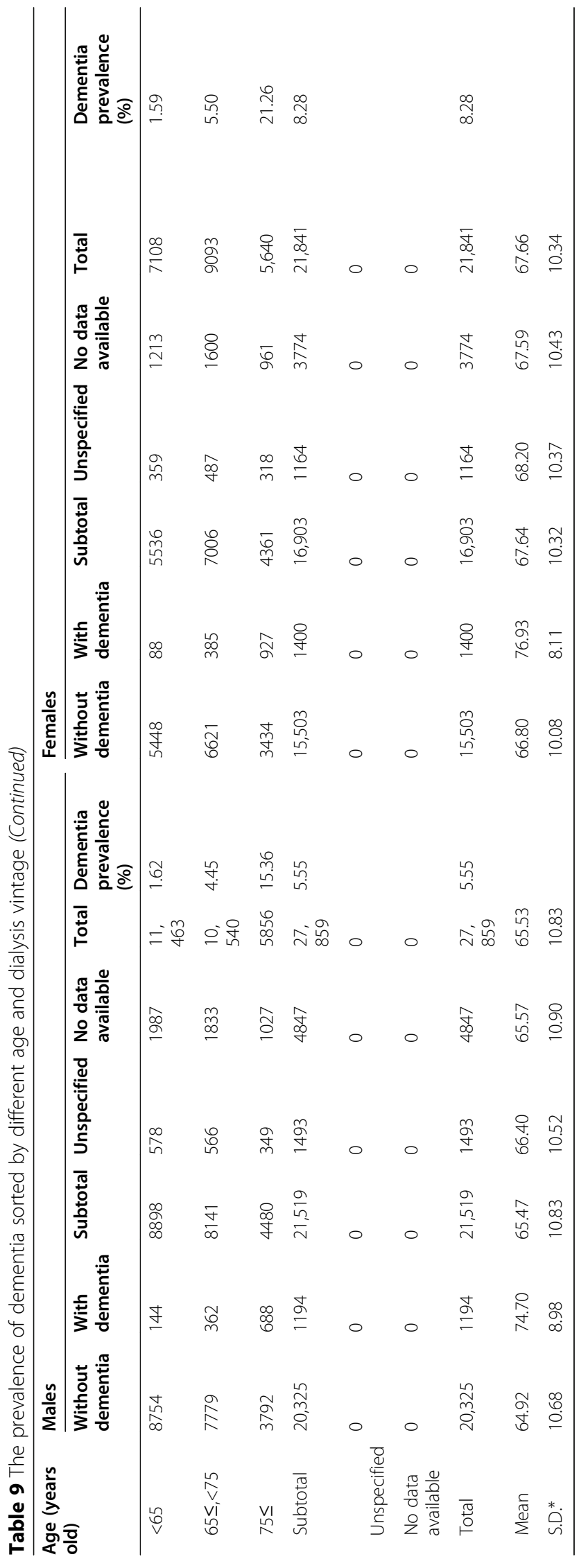


Table 10 The basic background factors of patients treated by main three kinds of dialysis methods

\begin{tabular}{lllll}
\hline $\begin{array}{l}\text { Treatment } \\
\text { methods }\end{array}$ & $\begin{array}{l}\text { Mean age (years } \\
\text { old) }\end{array}$ & $\begin{array}{l}\text { Mean dialysis vintage } \\
\text { (years) }\end{array}$ & $\begin{array}{l}\text { Percentage of male } \\
\text { patients }\end{array}$ & $\begin{array}{l}\text { Percentage of patients with } \\
\text { diabetes }\end{array}$ \\
\hline Facility hemodialysis & 70.0 & 6.7 & 65.2 & 57.5 \\
Hemodiafiltration & 67.2 & 8.4 & 65.9 & 53.9 \\
Peritoneal dialysis & 63.8 & 2.9 & 65.9 & 52.2 \\
\hline
\end{tabular}

Table 11 The basic background factors of patients sorted by different dialysis vintage

\begin{tabular}{|c|c|c|c|c|c|c|}
\hline \multirow[t]{2}{*}{ Background factors } & & \multicolumn{5}{|c|}{ Dialysis vintage (year) } \\
\hline & & $<5$ & $5 \leq_{,}<10$ & $10 \leq_{1}<20$ & $20 \leq$ & Total \\
\hline \multirow[t]{4}{*}{ Percentage of patients treated by each method } & Facility hemodialysis & 58.4 & 52.8 & 50.1 & 43.3 & 54.1 \\
\hline & Hemodiafiltration & 36.7 & 45.1 & 48.5 & 51.8 & 42.3 \\
\hline & Peritoneal dialysis & 4.8 & 1.9 & 0.6 & 0.2 & 2.9 \\
\hline & Others & 0.1 & 0.3 & 0.8 & 4.8 & 0.7 \\
\hline \multicolumn{2}{|l|}{ Percentage of male patients } & 68.8 & 66.7 & 62.0 & 53.8 & 65.7 \\
\hline \multicolumn{2}{|l|}{ Percentage of patients with diabetes } & 62.9 & 62.3 & 47.4 & 14.5 & 56.1 \\
\hline \multicolumn{2}{|l|}{ Mean age (years old) of each dialysis vintage patients } & 69.9 & 69.2 & 67.9 & 66.6 & 69.1 \\
\hline
\end{tabular}

This tabulation was performed on all dialysis patients

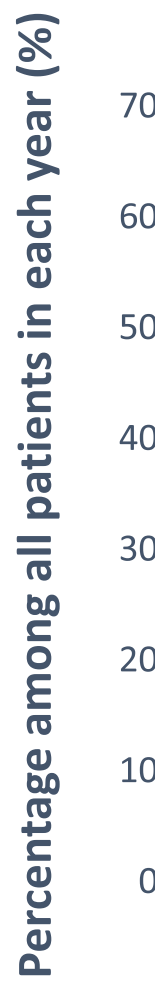

\section{8}

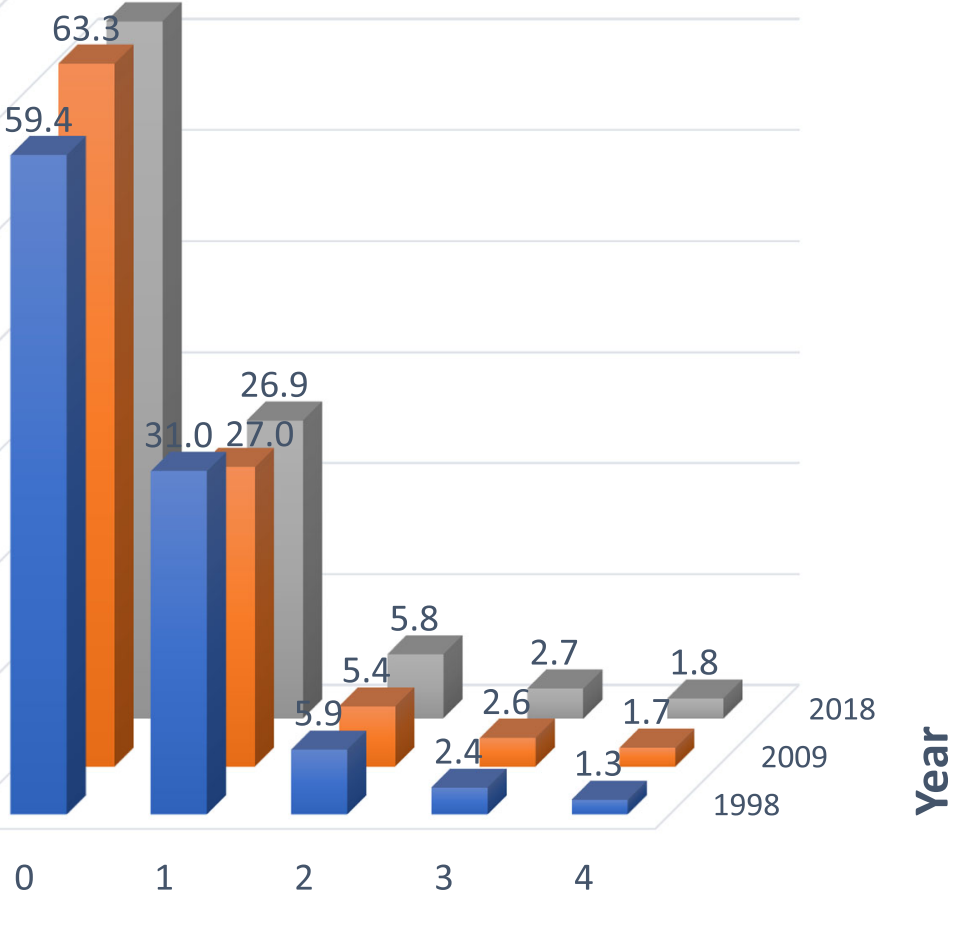

Performance status score

Fig. 11 Trend in performance status: under 60 years old. The numbers in the figure indicate the percentages for each year. Data in 1998 and 2018 are for all dialysis patients, while the data in 2009 is only for patients who were receiving hemodialysis at a facility 3 times/week. Data were obtained from the patient survey 


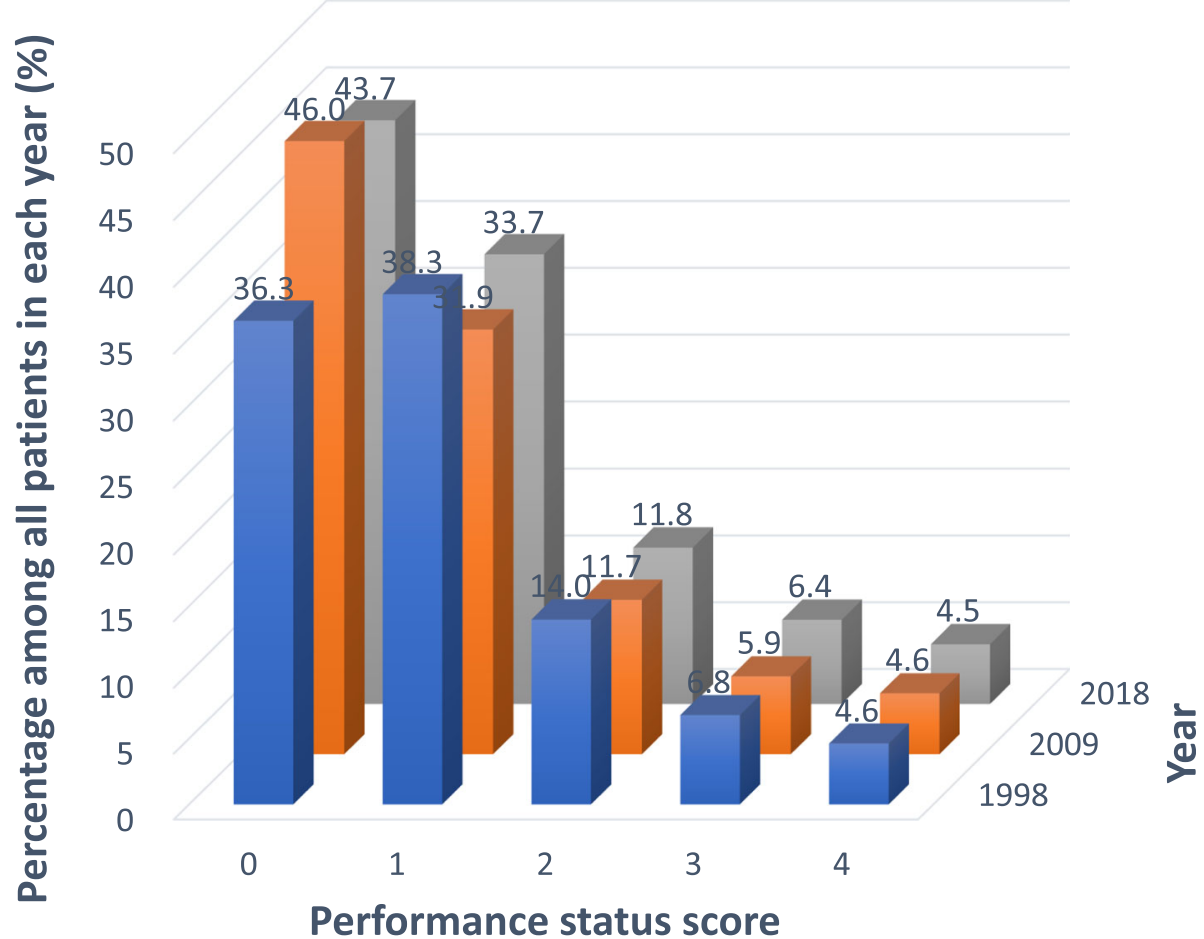

Fig. 12 Trend in performance status: 60-74 years old. The numbers in the figure indicate the percentages for each year. The data in 1998 and 2018 are for all dialysis patients, while the data in 2009 is only for those patients who were receiving hemodialysis at a facility 3 times/week. Data were obtained from the patient survey 


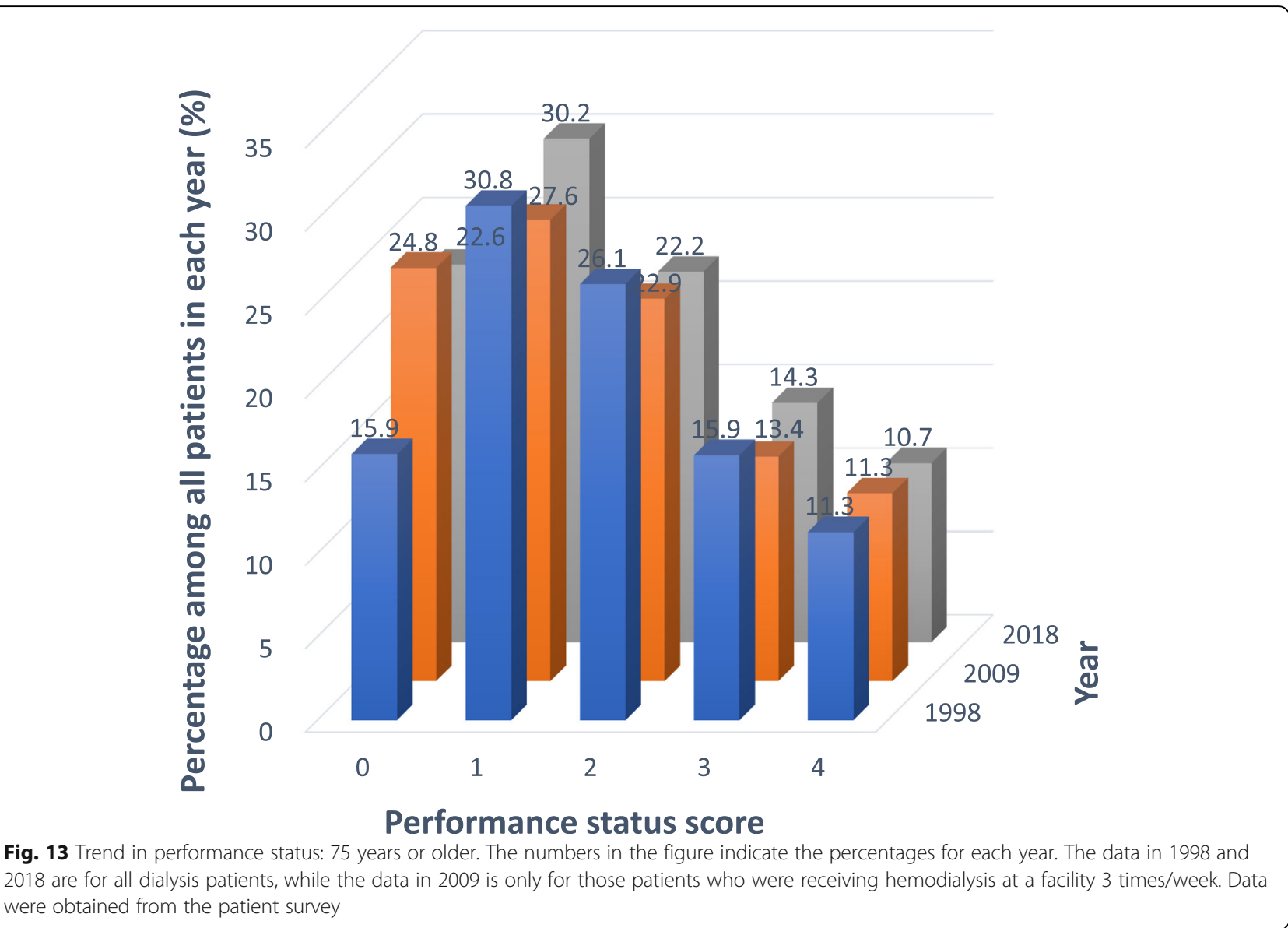

dialysis patients. The dementia prevalence in the dialysis patients overall was $10.8 \%$ (1.8\% in the less than 65 years age group, $6.8 \%$ in the $65-74$ years age group, and $22.7 \%$ in the 75 years or older age group). An analysis of the patients' PS revealed that the percentage of patients with low activity levels (high PS scores) tended to be relatively high in the less than 15-year-old and 60 years or older age groups. An analysis of the exercise habits revealed that the percentage of patients selecting the choice of "Not at all or hardly" was the highest $(60-80 \%)$ in each age group.

\section{Abbreviations}

HDS-R: Hasegawa dementia rating scale-revised; ICD10: 10th version of the International Classification of Diseases, Injuries, and Causes of Death; JRDR: JSDT Renal Data Registry; JSDT: Japanese Society for Dialysis Therapy; MMSE: Mini Mental State Examination; PS: Performance status; S.D.: Standard deviation; UMIN: University hospital Medical Information Network

\section{Supplementary Information}

The online version contains supplementary material available at https://doi. org/10.1186/s41100-021-00357-5.

Additional file 1: Supplementary Table 1. Dementia prevalence sorted according to age and sex.
Additional file 2: Supplementary Table 2. Dementia prevalence sorted according to age and diabetic status.

Additional file 3: Supplementary Table 3. Dementia prevalence sorted according to age and dialysis vintage.

Additional file 4: Supplementary Table 4. Performance status and age

Additional file 5: Supplementary Table 5. Exercise habits and age. Additional file 6: Supplementary Table 6. Exercise habits, age and dialysis vintage.

Additional file 7: Supplementary Table 7. Trends in dementia prevalence among hemodialysis patients treated three times a week.

Additional file 8: Supplementary Table 8. Trends in performance status.Additional file 8 of Annual dialysis data report 2018, JSDT Renal Data Registry; dementia, performance status and exercise habits

\section{Acknowledgements}

We owe the completion of this survey to the efforts of the members of the subcommittee for JRDR Regional Cooperation, the members of which are mentioned below, and the staff members of the dialysis facilities who participated in the survey and responded to the questionnaires. We would like to express our deepest gratitude to all these people.

Subcommittee for JRDR Regional Cooperation: Kazuyuki Maeno, Tetsuya Kawata, Chikara Oyama, Koji Seino, Toshinobu Sato, Shigeru Sato, Minoru Ito, Junichiro Kazama, Atsushi Ueda, Osamu Saito, Tetsuo Ando, Tomonari Ogawa, Hiroo Kumagai, Hiroyuki Terawaki, Ryoichi Ando, Masaki Abe, Tetsuya Kashiwagi, Chieko Hamada, Yugo Shibagaki, Nobuhito Hirawa, Hisaki Shimada, Yoichi Ishida, Hitoshi Yokoyama, Ryoichi Miyazaki, Mizuya Fukasawa, Yuji Kamijyo, Teppei Matsuoka, Akihiko Kato, Noriko Mori, Yasuhiko Ito, 
Hirotake Kasuga, Sukenari Koyabu, Tetsuro Arimura, Tetsuya Hashimoto, Masaaki Inaba, Terumasa Hayashi, Tomoyuki Yamakawa, Shinichi Nishi, Akira Fujimori, Tatsuo Yoneda, Shigeo Negi, Akihisa Nakaoka, Takafumi Ito, Hitoshi Sugiyama, Takao Masaki, Yutaka Nitta, Kazuyoshi Okada, Masahito Yamanaka, Masaharu Kan, Kazumichi Ota, Masahito Tamura, Koji Mitsuiki, Yuji Ikeda, Masaharu Nishikido, Akira Miyata, Tadashi Tomo, Shoichi Fujimoto, Tsuyoshi Nosaki, and Yoshinori Oshiro.

\section{Consortia}

on behalf of the Japanese Society for Dialysis Therapy Renal Data Registry Committee

Kazuyuki Maeno, Tetsuya Kawata, Chikara Oyama, Koji Seino, Toshinobu Sato, Shigeru Sato, Minoru Ito, Junichiro Kazama, Atsushi Ueda, Osamu Saito, Tetsuo Ando, Tomonari Ogawa, Hiroo Kumagai, Hiroyuki Terawaki, Ryoichi Ando, Masaki Abe, Tetsuya Kashiwagi, Chieko Hamada, Yugo Shibagaki, Nobuhito Hirawa, Hisaki Shimada, Yoichi Ishida, Hitoshi Yokoyama, Ryoichi Miyazaki, Mizuya Fukasawa, Yuji Kamijyo, Teppei Matsuoka, Akihiko Kato, Noriko Mori, Yasuhiko Ito, Hirotake Kasuga, Sukenari Koyabu, Tetsuro Arimura, Tetsuya Hashimoto, Masaaki Inaba, Terumasa Hayashi, Tomoyuki Yamakawa, Shinichi Nishi, Akira Fujimori, Tatsuo Yoneda, Shigeo Negi, Akihisa Nakaoka, Takafumi Ito, Hitoshi Sugiyama, Takao Masaki, Yutaka Nitta, Kazuyoshi Okada, Masahito Yamanaka, Masaharu Kan, Kazumichi Ota, Masahito Tamura, Koji Mitsuiki, Yuji Ikeda, Masaharu Nishikido, Akira Miyata, Tadashi Tomo, Shoichi Fujimoto, Tsuyoshi Nosaki \& Yoshinori Oshiro.

\section{Authors' contributions}

$\mathrm{KN}, \mathrm{IM}, \mathrm{MT}$, and SN finalized the results of the survey and prepared this manuscript. SN, $\mathrm{NH}$, and AW designed the survey sheets and made a special program operating within an MS Excel worksheet for the convenience of the self-assessments of dialysis quality made by each dialysis facility. T. Hase, T. Hama, JH, NJ, KM, SG, and MA were responsible for the data analysis. KY and IM were responsible for the ethics of the JRDR survey. HN was the president of JSDT in 2018, checked all the results from the 2018 JRDR survey, and approved their publication. The authors read and approved the final manuscript.

\section{Funding}

The present study did not receive any funding.

All efforts and costs for the 2018 JRDR survey and the creation of the ADR were provided by JSDT.

\section{Availability of data and materials}

For anyone wanting to use the data and materials from the current manuscript without modifications, all the data and materials will be freely available provided that "data from the JSDT" is stated.

Anyone wanting to use the data and materials from the current manuscript with modifications or re-calculations, etc., must include the following sentence in their publication: "The data reported here have been provided by the Japanese Society for Dialysis Therapy (JSDT). The interpretation and reporting of these data are the responsibility of the authors and should in no way be seen as an official policy or interpretation of the JSDT."

\section{Declarations}

\section{Ethics approval and consent to participate}

The JRDR was approved by the ethics committee of the JSDT (approval no. 1) and was registered in the "University hospital Medical Information Network (UMIN) Clinical Trials Registry" under the clinical trial ID of UMIN000018641 on August 8, 2015: (Accessed June 2, 2020).

The aims of the JSDT Renal Data Registry (JRDR) were well explained to the participating dialysis patients at the dialysis facilities.

Documented approval forms from the patients were not required because all the data had already been collected, and there were no new interventions.

The original data was totally anonymized to avoid any risk of compromising the privacy of the dialysis facilities and the patients.

The data presented in the current manuscript does not contain any images, videos, or voice recording that could be used to identify an individual.

\section{Consent for publication}

Not applicable

\section{Competing interests}

The authors declare that they have no competing interests.

Received: 8 January 2021 Accepted: 11 June 2021

Published online: 13 July 2021

References

1. Nakai S. The history of Japanese Society for Dialysis Therapy Registry. J Jpn Soc Dial Ther. 2010;43(2):119-52. (in Japanese). https://doi.org/10.4009/ jsdt.43.119.

2. Masakane I, Nakai S. Recent trends of chronic dialysis in Japan from the viewpoint of the JSDT Renal Data Registry. J Jpn Soc Dial Ther. 2016;49(3): 211-8. (in Japanese). https://doi.org/10.4009/jsdt.49.211.

3. Nitta K, Masakane I, Hanafusa N, Goto S, Abe M, Nakai S, et al. Annual dialysis data report 2018, JSDT Renal Data Registry. J Jap Soc Dial Ther. 2019;52(12):679-754. (in Japanese). https://doi.org/10.4009/jsdt.52.679.

4. National Cancer Institute, National Institutes of Health. Common toxicity criteria, version2.0 Publish Date April 30, 1999. http://ctep.cancer.gov/ protocolDevelopment/electronic_applications/docs/ctcv20_4-30-992.pdf. (April 2020).

5. Nitta K, Goto S, Masakane I, Hanafusa N, Taniguchi M, Hasegawa T, et al. Annual dialysis data report for 2018, JSDT Renal Data Registry: survey methods, facility data, incidence, prevalence, and mortality. Ren Replace Ther. 2020;6(1):41. https://doi.org/10.1186/s41100-020-00286-9.

6. Nakai S, Masakane I, Akiba T, Shigematsu T, Yamagata K, Watanabe Y, et al. Overview of regular dialysis treatment in Japan as of 31 December 2006. Ther Apher Dial. 2008;12(6):428-56. https://doi.org/10.1111/j.1744-9987.2008. 00634.x.

7. Nakai S, Masakane I, Shigematsu T, Hamano T, Yamagata K, Watanabe Y, et al. An overview of regular dialysis treatment in Japan (as of 31 December 2007). Ther Apher Dial. 2009;13(6):457-504. https://doi.org/10.1111/j.17449987.2009.00789.x.

8. Nakai S, Iseki K, Itami N, Ogata S, Kazama JJ, Kimata N, et al. Overview of regular dialysis treatment in Japan (as of 31 December 2009). Ther Apher Dial. 2012;16(1):11-53. https://doi.org/10.1111/j.1744-9987.2011.01050.x.

9. Nakai S, Iseki K, Itami N, Ogata S, Kazama JJ, Kimata N, et al. An overview of regular dialysis treatment in Japan (as of 31 December 2010). Ther Apher Dial. 2012;16(6):483-521. https://doi.org/10.1111/j.1744-9987.2012.01143.x.

10. World Health Organization. International Statistical Classification of Diseases and Related Health Problems. 10 ${ }^{\text {th }}$ Revision. Geneva: World Health Organization; 1993.

11. Japanese Society of Neurology. Dementia disease medical treatment guideline 2017. Tokyo: Igakushoin; 2017.

12. Japanese Society for Dialysis Therapy Renal Data Registry. An overview of dialysis treatment in Japan (as of Dec. 31, 1998). J Jap Soc Dial Ther. 2000;33(1):1-27.

13. Nakai S, Shinzato T, Nagura Y, Masakane I, Kitaoka T, Shinoda T, et al. An overview of regular dialysis treatment in Japan (as of December 2002). Ther Apher Dial. 2004:8(5):358-82.

14. World Health Organization and Alzheimer's disease international. Dementia: a public health priority. http://www.who.int/mental_health/publications/ dementia_report_2012/en/. Accessed 7 Mar 2021.

15. Konagaya $Y$, Watanabe $T$, Konaga $M$. Frequency and clinical characteristics of the individuals with presenile dementia in Aichi prefecture. Clin Neurol. 2009;49(6):335-41.

16. Kopf D, Frölich L. Risk of incident Alzheimer's disease in diabetic patients: a systematic review of prospective trials. J Alzheimers Dis. 2009;16(4):677-85. https://doi.org/10.3233/JAD-2009-1011.

17. Nakai S, Wakai K, Kanda E, Kawaguchi K, Sakai K, Kitaguchi N. Is hemodialysis itself a risk factor for dementia? An analysis of nationwide registry data of patients on maintenance hemodialysis in Japan. Renal Replace Ther. 2018;4, 4(12, 1) https://doi.org/10.1186/s41100-018-0154-y.

18. Forbes D, Thiessen EJ, Blake CM, Forbes SC, Forbes S. Exercise programs for people with dementia. Cochrane Database Syst Rev. 2013;4(12):CD006489.

19. Littbrand $H$, Stenvall M, Rosendahl E. Applicability and effects of physical exercise on physical and cognitive functions and activities of daily living among people with dementia: a systematic review. Am J Phys Med Rehabil. 2011;90(6):495-518. https://doi.org/10.1097/PHM.0b013e318214de26.

\section{Publisher's Note}

Springer Nature remains neutral with regard to jurisdictional claims in published maps and institutional affiliations. 